\title{
Desempenho Macroeconômico e Taxa de Pobreza Estadual no Brasil no Período 1981-2006*
}

\section{Macroeconomic Performance and State Poverty Rate in Brazil during 1981-2006}

\author{
Julio Cesar dos Reis** \\ Frederico G. Jayme Júnior* * * \\ Ana Maria Hermeto Camilo de Oliveira****
}

Resumo: As discussões sobre a pobreza sempre estiveram presentes no âmbito da teoria econômica. Contudo, são relativamente escassos, ainda mais na literatura brasileira, trabalhos que relacionam a pobreza ao desempenho macroeconômico mesmo sendo senso comum a relevância da atividade econômica para a determinação da condição de pobreza. Assim sendo, o presente trabalho tentará inserir a discussão do combate à pobreza no âmbito da formulação e da implementação da política macroeconômica considerando as relações entre o desempenho macroeconômico e a taxa de pobreza. Para investigar essas relações, utilizaremos um painel de dados formados por informações referentes aos estados brasileiros no período de 1981 a 2006. Como principal resultado, o trabalho evidencia que estratégias de crescimento econômico, se tomadas isoladamente, são insuficientes. Vários aspectos estruturais condicionam as relações entre o desempenho econômico e o bem estar da população. Dessa forma, além de que crescimento econômico contínuo, sustentável e equilibrado, é necessário romper as estruturas que, principalmente nos países subdesenvolvidos, levam ao conhecido processo de crescimento com concentração de renda.

Palavras-chave: Desempenho macroeconômico. Políticas macroeconômicas. Taxa de pobreza.

\footnotetext{
* Os autores gostariam de agradecer aos pareceristas anônimos da revista pelos comentários e sugestões. Quaisquer erros remanescentes são de inteira responsabilidade dos autores. Os autores também agradecem ao CNPq e a FAPEMIG pelo suporte financeiro.

** Pesquisador da Embrapa Agrossilvipastoril. Mestre em Economia pelo Centro de Desenvolvimento e Planejamento Regional (CEDEPLAR) da Universidade Federal de Minas Gerais (UFMG). E-mail: julio.reis@embrapa.br.

*** Professor do Centro de Desenvolvimento e Planejamento Regional (CEDEPLAR) da Universidade Federal de Minas Gerais (UFMG). E-mail: gonzaga@cedeplar.ufmg.br

**** Professora adjunta do Centro de Desenvolvimento e Planejamento Regional (CEDEPLAR) da Universidade Federal de Minas Gerais (UFMG). E-mail: ahermeto@cedeplar.ufmg.br
} 
Abstract: Discussions on poverty always were present in the scope of the economic theory. However, papers that relate the poverty to the macroeconomic performance are relatively scarce, still more in the Brazilian literature, even being common sense the relevance of the economic activity for the determination of the condition of poverty. So, the present work will try to insert the discussion about the battle against poverty in the scope of the formulation and of the implementation of the macroeconomic policies considering the relations between the macroeconomic performance and the poverty rate. To investigate those relations, we will utilize panel data of information regarding the Brazilian states in the period of 1981 to 2006. As most important result, this work shows that only economic growth strategies are insufficient. Many structural aspects determine the relations between economic performance and welfare of population. Thus, besides that continuous, sustainable and balanced economic growth, is necessary to break the structures that, mainly in underdevelopment countries, induce to the known process of growth with income concentration.

Keywords: Macroeconomic performance. Macroeconomic policies. Poverty rate. JEL Classification: E00; E30; I32.

\section{Introdução}

O objetivo deste trabalho é investigar as relações entre o desempenho macroeconômico e o padrão de vida da população nos estados brasileiros no período de 1981 a 2006. Vários são os determinantes e condicionantes dessa relação bem como os canais através dos quais essa relação se processa. Entretanto, as relações entre o desempenho macroeconômico e a evolução do padrão de vida da população foram pouco exploradas, ressaltando que, em geral, essa discussão se relaciona aos aspectos estruturais como características do domicílio, a distribuição dos ativos e bens entre as famílias e os preços desses bens, concentrando a análise nas características do indivíduo e deixando em segundo plano os aspectos relacionados ao meio no qual esse indivíduo está inserido.

Contudo, é importante delimitar a proposta de análise do trabalho em virtude da amplitude do assunto. A determinação do padrão de vida de uma população não é trivial, uma vez que envolve aspectos econômicos, sociais, culturais, políticos, biológicos que, em muitos casos, são difíceis de mensurar e de ponderar para a construção de uma ordenação passivel de comparação. Para lidar com esses problemas adotaremos como medida para o padrão de vida a taxa de pobreza. Isso porque entendemos ser esse o conceito que nos fornece informações capazes de captar as relações aqui propostas, já que indica como a população se apropriados benefícios da atividade econômica. 
Não obstante, o conceito de pobreza também é amplo. De forma não simplificada, a condição de pobreza apresenta um aspecto multidimensional, ou seja, pode compreender fatores variados relacionados a uma imensa quantidade de privações, sejam monetárias ou relacionadas à capacidade de acesso a bens, serviços e direitos. Para lidar com as dificuldades conceituais e, ao mesmo tempo, facilitar a mensuração e propiciar um instrumento de análise, será aqui adotada uma medida unidimensional da pobreza, sintetizada na insuficiência de renda. Em que pese a limitação da análise ao âmbito monetário, esse aspecto nos permite estabelecer importantes relações no tocante aos efeitos da atividade econômica sobre o padrão de vida da população.

A discussão sobre a pobreza é recorrente no âmbito da teoria econômica. Contudo, são relativamente escassos na literatura brasileira trabalhos que relacionam a pobreza ao desempenho macroeconômico a nível estadual. Nesse sentido destacam-se os trabalhos de Barreto, Marinho e Soares (2003), Hoffmann (2005) e Tochetto et al. (2004).

Barreto, Marinho e Soares (2003) estimam as elasticidades da renda média mensal estadual sobre a pobreza entre 1985 e 1999. Esses autores, seguindo metodologia proposta por Kakwani (1990) e Ravallion e Datt (1992) decompõem a variação na incidência da pobreza em dois termos: um resultante do crescimento econômico e outro que é função da concentração de renda. Os resultados ressaltam que renda média maior se relaciona com maior elasticidade (em valor absoluto), ao passo que maior concentração de renda se relaciona com menores elasticidades. Ainda, com relação à decomposição, os resultados mostraram que o aumento da renda contribuiu relativamente mais do que a concentração da renda para reduzir a pobreza. Todavia, os resultados mostraram que para se obter uma determinada redução na medida de pobreza, a variação necessária na concentração de renda é menor do que a variação necessária na renda média.

Hoffmann (2005) também analisa a elasticidade da proporção de pobres em relação à renda média e ao índice de Gini da distribuição da renda domiciliar per capita no Brasil, nos estados e nas grandes regióes do país. Para tanto, apresenta uma metodologia para calcular a elasticidade da proporção de pobres em relação ao rendimento médio e em relação ao índice de Gini, pressupondo que a distribuição de renda assume uma distribuição de probabilidade log-normal. As elasticidades renda-pobreza foram calculadas para os anos de 1999, 2001 e 2002. Como, segundo o próprio autor, esse trabalho foi motivado pelo trabalho de Barreto, Marinho e Soares (2003) discutido anteriormente, os resultados encontrados para o ano de 1999 foram comparados com o referido trabalho e, apesar de serem baseados em metodologias diferentes, o padrão de variação das elasticidades entre os estados se mostrou muito semelhante, não obstante as estimativas das elasticidades em Barreto, Marinho e Soares (2003) seja maiores em termos absolutos. 
Por fim, Tochetto et al. (2004) analisa a qualidade do crescimento econômico nos estados brasileiros durante as décadas de 1980 e 1990. Para tanto é processado o cálculo das elasticidades do crescimento em relação à pobreza tendo em conta as diferenças interestaduais e, ainda, é estimada a curva de crescimento pobreza de Son (2004) para os estados considerando o período analisado. Para o cálculo das elasticidades o autor utilizou a metodologia proposta por Ravallion e Datt (2002) incluindo na estimação informações de gastos governamentais per capita com educação e estimativas de inflação das 10 principais regiões metropolitanas obtidas em Menezes e Azzoni (1999). Como principais resultados, o trabalho mostrou que em apenas duas localidades - Distrito Federal e Ceará - o crescimento foi capaz de reduzir a incidência da pobreza. Concluiu, ademais, que os gastos governamentais com educação se comportaram de forma contrária ao esperado, ou seja, os gastos em educação tiveram um efeito negativo sobre a redução na pobreza. A queda na inflação, por seu turno, favoreceu a diminuição da pobreza. Com relação aos resultados para a curva crescimento-pobreza o autor mostrou que os anos 1980 geraram um crescimento pró-ricos, vale dizer, os períodos de rápido crescimento, em média, assistiram ao aumento dos decis de renda mais elevada, diferentemente da década de 1990.

O presente trabalho procura avançar a partir desta literatura ao incorporar, além da desigualdade de renda, um conjunto de variáveis macroeconômicas que influenciam, direta ou indiretamente, a pobreza. Ainda, procura inserir a pobreza no âmbito da formulação e implementação da política macroeconômica, ao discutir as implicações dos resultados do desempenho macroeconômico, que é função direta das políticas adotadas, sobre a população mais pobre.

Embora a estimativa da elasticidade renda-pobreza também seja feita no presente trabalho, a inclusão de variáveis socioeconômicas busca caracterizar e controlar os efeitos dessas outras informações sobre a pobreza. Assim, além do desempenho macroeconômico, a consideração do meio no qual o indivíduo está inserido pode fornecer relevantes informações para a determinação de sua condição de pobreza. Outro ponto que diferencia esse trabalho é o fato de relacionar a taxa de pobreza estadual a outras variáveis que caracterizam o desempenho macroeconômico como a taxa de atividade e a taxa de desemprego. Em que pese o fato de apresentarem forte correlação com o nível de renda, elas permitem inferências difíceis de se obterem a partir da renda agregada, como, por exemplo, a consideração dos efeitos diretos da renda advinda do trabalho, bem como a relação entre a PEA e a PIA e seus desdobramentos sobre a pobreza. Ainda, vale pontuar que o presente trabalho considera um período de tempo maior do que os demais, tendo assim a possibilidade de captar melhor importantes mudanças na estrutura da economia brasileira, como a consolidação dos efeitos do plano real, os efeitos da mudança na condução da política monetária implementados em 
1999, bem como os programas de transferência de renda fortalecidos pelo atual governo, sobre a incidência de pobreza nos estados brasileiros.

Para tratar das relações entre o desempenho macroeconômico e a taxa de pobreza estadual utilizaremos um modelo para dados em painel tendo como fonte principal de informações a Pesquisa Nacional de Amostra Domiciliar (PNAD), do Instituto Brasileiro de Geografia e Estatística (IBGE).

Assim sendo, além dessa introdução, o presente trabalho apresenta mais quatro itens. O primeiro se concentrará nas relações entre o desempenho macroeconômico e a taxa de pobreza dentro de uma perspectiva teórica, ressaltando alguns aspectos estruturais que condicionam e determinam os efeitos da economia sobre o padrão de vida da população. $\mathrm{O}$ item seguinte se incumbe de apresentar o método de análise e os procedimentos econométricos. Para a análise proposta utilizaremos como indicadores de desempenho macroeconômico a taxa de atividade estadual, a taxa de desemprego estadual e a massa da renda familiar real. Ainda, como forma de considerar os fatores estruturais acima referidos um conjunto de variáveis de controle será introduzido nas estimações. Esse conjunto será formado por variáveis que representam características demográficas e variáveis que representam características socioeconômicas importantes na determinação da condição de pobreza. Na sequência é desenvolvida uma seção de análise dos resultados. Por fim, a última parte será destinada às considerações finais.

\section{Crescimento Econômico e Pobreza}

Há uma vasta literatura que atesta a eficácia do crescimento econômico para a elevação do padrão de vida ${ }^{1}$ e a maioria dos trabalhos que tratam desse tema dentro de uma perspectiva macroeconômica têm como fundamento teórico, para evidenciar a relação crescimento-pobreza, a perspectiva conhecida na literatura como trickle-down efect. Vale dizer, o crescimento econômico tende a aumentar a taxa de emprego, o que proporciona um aumento no nível de salários, aumento da renda e, consequentemente, queda na pobreza (AGHION; BOLTON, 1997). Dessa forma, dotar o sistema econômico de instrumentos, sejam políticos, econômicos ou sociais, que facilitem a propagação dos efeitos do crescimento econômico é uma importante estratégia para combater a pobreza.

Dentro deste arcabouço teórico, três aspectos são frequentemente considerados como os principais determinantes do crescimento econômico: investimento, expansão do comércio exterior e desenvolvimento do sistema financeiro.

1 Agenor (2001), Aghion e Bolton (1997), Barros e Mendonça (1997), Blank e Card (1993), Bourguignon (2004), Cutler e Katz (1993), Dollar e Kraay (2002), Ravallion e Chen (1996), Thirlwall (2005).

REIS, J. C.; JAYME JÚNIOR, F. G; OLIVEIRA, A. M. H. C. Desempenho Macroeconômico e... 
É uma questão consolidada na literatura que altos níveis de investimento tendem a levar a altas taxas de crescimento econômico, mesmo considerando que existem fatores institucionais, políticos e sociais que influenciam nessa causalidade. Assim, na ausência de fatores que impeçam e/ou limitem a transferência dos benefícios do crescimento para os mais pobres, altas taxas de investimento levam a altas taxas de crescimento econômico, o que representa aumento de emprego e de salário. Este círculo virtuoso pode reduzir a pobreza, dependendo, naturalmente, do seu efeito sobre a distribuição da renda.

A expansão do comércio exterior e sua relação com o crescimento econômico e com a redução da pobreza é mais controversa. Adeptos da liberalização acreditam que a ampliação do comércio com o setor externo pode criar novas oportunidades de negócios, proporcionando acesso a novos mercados tanto para produtores como para consumidores; também consideram que a abertura comercial pode proporcionar aumentos de produtividade via especialização, tanto da mão de obra como da capacidade instalada via economias de escala e através do acesso a novas tecnologias e formas organizacionais. Ainda, ao aumentar a competitividade, essa estratégia pode elevar a capacidade de crescimento da economia, uma vez que as empresas menos competitivas serão naturalmente expulsas do mercado ficando somente aquelas com maior produtividade, consequentemente, com maior capacidade de crescimento.

Por outro lado, há os que não consideram a liberalização fundamental, pois entendem que a abertura comercial pode gerar efeitos negativos sobre o perfil distributivo e, dessa forma, sobre a capacidade do crescimento econômico reduzir a pobreza. ${ }^{2}$ Ademais, entendem que a liberalização comercial pode produzir uma reestruturação do sistema produtivo no sentido de aumentar a concentração de mercado ao invés de garantir maior concorrência (ARESTIS, 2004). Ainda, a abertura comercial pode dificultar o equilíbrio externo implicando em déficits comerciais sucessivos o que, em última instancia, representa uma restrição externa ao processo de crescimento econômico (THIRLWALL, 2005). Nesse sentido, as principais consequências negativas relacionadas às modificações na organização produtiva são o aumento do número de desempregados, principalmente os que possuem menores níveis de escolaridade e produtividade, em geral os mais pobres, e uma falência das empresas que não suportam a competição internacional. ${ }^{3}$

Por fim, no que concerne ao desenvolvimento do sistema financeiro e sua relação com o crescimento econômico, de acordo com a visão tradicional, a liberalização financeira tende a aumentar a taxa de poupança através do aumento real

2 Para uma ampla discussão sobre os efeitos da liberalização sobre um vasto conjunto de economias latino-americanas, ver: Stallings e Peres (2002) e Ocampo e Taylor (1998). Para uma análise do caso brasileiro, ver: Baumann (2000).

3 O cenário apresentado pelos países latino-americanos, e em especial o Brasil na década de 1990, condiz muito com esta realidade. 
da taxa de juros e alocá-la de maneira mais eficiente, aproveitando as oportunidades mais produtivas e, assim, proporcionando maior crescimento econômico. Além disso, a liberalização da conta de capitais tende a favorecer a eficiência na alocação de recursos nos mercados financeiros mundiais, proporcionando maiores possibilidades de crescimento econômico. Conforme esta perspectiva, a integração financeira de um país considerado pobre em relação ao resto do mundo pode representar ganhos em diversos aspectos:

a) um aumento no nível de investimentos externos pode ocorrer caso o país ofereça oportunidades com altos retornos;

b) com o aumento da possibilidade de diversificar os riscos, investimentos anteriormente considerados arriscados podem ser, agora, considerados economicamente viáveis;

c) a integração financeira pode aumentar a eficiência do sistema financeiro, seja através de organização, legislação ou melhora na qualidade dos serviços em virtude da competitividade.

Por outro lado, os críticos dessa perspectiva enfatizam que os possíveis resultados positivos da liberalização financeira são altamente dependentes das supo-sições feitas para a defesa deste argumento. Neste sentido, dois pontos importantes são: a excessiva crença na eficiência dos mercados e a suposição de que a taxa de poupança tende a aumentar com a liberalização financeira. Dentro de um arcabouço microeconômico, a existência de informação assimétrica em um cenário de altas taxas de juros pode levar a importantes restrições no mercado de crédito, numa tentativa por parte das instituições financeiras de evitar o fenômeno da seleção adversa. Assim, considerando essa possibilidade de limitação do crédito, a liberalização financeira pode, ao invés de reduzir a pobreza via crescimento, aumentá-la. De acordo com Arestis (2004), a liberalização financeira, ao promover o desenvolvimento do sistema financeiro, pode melhorar o acesso ao crédito de empresas e pessoas antes marginalizadas nessa atividade. Com o aumento das taxas de juros, há um aumento na taxa de poupança e, consequentemente, um aumento na oferta de crédito. Contudo, a não ser que existam legislações ou instituições regu-ladoras que imponham ao sistema financeiro metas de empréstimos para classes e atividades específicas, esse aumento de crédito não necessariamente significa aumento do volume de empréstimos para as pequenas e médias empresas como também para os mais pobres.

\subsection{Crescimento Econômico e Pobreza: o Crescimento é Benéfico a Todos?}

Há um relativo consenso sobre os efeitos positivos do crescimento econômico em minimizar a pobreza. Todavia, não necessariamente os benefícios de um bom desempenho econômico são observados por todos. Ao contrário, a concepção de que o crescimento econômico pode gerar concentra- 
ção de renda não é nova e é corroborada em muitas economias ao redor do mundo, sendo a economia brasileira um exemplo. Assim, a "visão tradicional" de rising tide lifts all boats - uma maré alta movimenta todos os barcos - sobre o relacionamento entre o crescimento e a pobreza pode não se aplicar. Muitos dos pobres residuais têm características que limitam sua inserção no mercado de trabalho ou que limitam seus salários e horas trabalhadas. A proporção da população adulta economicamente ativa que se encaixa nesta situação impõe um limite mínimo sobre a redução potencial na pobreza.

\subsection{Crescimento Econômico e Pobreza no Brasil: \\ os Efeitos da Desigualdade de Renda}

Considerando as limitações do crescimento econômico em minimizar a pobreza, uma característica estrutural chave para entender e explicar a possível fraqueza nessa relação é a desigualdade de renda. Os impactos do processo de crescimento econômico sobre a pobreza dependem fundamentalmente das mudanças na distribuição de renda que são desencadeadas por esse mesmo crescimento.

Assim, sendo a distribuição de renda brasileira uma das mais desiguais do mundo, a análise da relação entre o desempenho macroeconômico e a pobreza no Brasil deve dar uma atenção especial ao papel desempenhado pela desigualdade de renda, além de considerar o efeito dessa sobre a própria dinâmica do sistema econômico brasileiro. Dados da PNAD revelam uma incômoda estabilidade para o Índice de Gini no Brasil no período 1981-2006 em torno de 0,6, embora este tenha caído nos últimos anos, apresentando em 2006 o valor de 0,563 o que mantém o Brasil entre os países mais desiguais do mundo. ${ }^{4}$

Os efeitos positivos da redução na desigualdade de renda sobre o nível de pobreza podem ser observados empiricamente nos últimos cinco anos. Com um crescimento medíocre do PIB, média anual de 2,5\%, a considerável queda observada no nível de pobreza, cerca de $10 \%$, é diretamente relacionada à queda na desigualdade, mesmo essa queda sendo relativamente pequena - cerca de 4,6\% medida pelo Índice de Gini (IPEA, 2006). Barros et al. (2007b) apontam que a renda per capita dos mais pobres cresceu substancialmente entre 2001 e 2005, apesar da relativa estagnação da renda per capita nacional. ${ }^{5}$ Houve um crescimento anual de $8 \%$ para os $10 \%$ mais pobres e de $5,9 \%$ para os $20 \%$ mais pobres, ao passo que a renda dos $10 \%$ mais ricos declinou $0,3 \%$ e a dos $20 \%$ mais ricos caiu $0,1 \%$. Mais especificamente, a taxa de crescimento da renda dos $10 \%$ mais pobres foi 37 pontos

$4 \quad$ É importante notar que o grau de desigualdade é tão elevado que o coeficiente de Gini acaba sendo pouco afetado mesmo por melhorias significativas do rendimento na base da distribuição, como as que ocorreram logo após o Plano Real (ROCHA, 2000).

5 Importante ressaltar que para esses números, em função da limitação de informações, não é considerada a renda advinda da remuneração de ativos financeiros. 
percentuais maior que a dos $10 \%$ mais ricos e a taxa de crescimento da renda dos $20 \%$ mais pobres foi 26 p.p. superior à dos $20 \%$ mais ricos. $^{6}$

Além dessa análise agregada dos efeitos da redução na desigualdade sobre a pobreza, é importante levar em consideração os determinantes dessa queda e, principalmente, a relação desses com a queda na pobreza. Barros et al. (2007a), a partir de uma análise contrafactual, identificaram como principais determinantes da queda da desigualdade nos últimos anos a expansão das transferências governamentais e as mudanças ocorridas no mercado de trabalho. Segundo esse estudo, cerca de 50\% do declínio da desigualdade resultou da evolução da renda não derivada do trabalho, principalmente das transferências governamentais, apesar desta representar menos de um quarto da renda total. Mudanças na distribuição da renda do trabalho explicam cerca de um terço da queda observada na desigualdade, embora essa renda represente mais de três quartos da renda total.

Uma análise da importância dos programas de transferência para combater a pobreza no Brasil nos últimos anos foi realizada por Soares et al. (2006) com base nos dados da PNAD de 2004. Este trabalho mostrou que os programas de transferências são bem focalizados: as famílias mais pobres recebem a maior parte dos recursos transferidos por esses programas e é praticamente irrelevante o número de beneficiários entre a população de renda mais alta. Além disso, as transferências reduzem a incidência e a intensidade da pobreza bem como a desigualdade. Ainda, neste mesmo estudo, é possível observar, como esperado, que todas as transferências de renda promovem a redução da pobreza. Contudo, em razão dos valores transferidos, o Benefício de Prestação Continuada (BPC), ${ }^{7}$ as pensões e as aposentadorias do piso de um salário mínimo são capazes de retirar as famílias da indigência e da pobreza, ao passo que os demais programas de transferência de renda melhoram a situação das famílias sem, no entanto, serem suficientes para retirar todas elas da condição de pobreza. Em outras palavras, enquanto o BPC, as aposentadorias e as pensões do piso de um salário mínimo

6 Em geral, o impacto do crescimento econômico sobre a pobreza é tanto maior quanto menor for a desigualdade na distribuição de renda. Reduções no grau de desigualdade não apenas têm impacto direto sobre a pobreza, como também elevam a capacidade do crescimento econômico beneficiar os mais pobres. É evidente que o inverso também é verdadeiro: o crescimento não apenas tem impacto direto sobre a pobreza, como também eleva a capacidade de futuras reduções no grau de desigualdade reduzirem a pobreza (BARROS et al., 2007b).

7 O Benefício de Prestação Continuada é uma transferência de renda, sem condicionalidades e independente de contribuição prévia para o regime de seguridade social, para idosos com 65 anos ou mais e pessoas com deficiência, não aptas ao trabalho e a uma vida independente, que vivem em famílias com renda familiar per capita abaixo de um quarto do salário mínimo. Previsto na Constituição Federal, o BPC começou a ser implementado a partir de 1996. O valor do benefício é igual a um salário mínimo. No caso de deficientes, médicos peritos avaliam sua condição física e mental para uma vida independente e de trabalho. Os beneficiários - tanto idosos como deficientes - são reavaliados a cada dez anos para examinar se sua situação de extrema pobreza mudou. O benefício pode ser cancelado caso a situação da família não seja mais de extrema pobreza. 
têm impacto claro e direto sobre a incidência e a intensidade da pobreza, as demais transferências têm efeito forte apenas sobre a intensidade da pobreza. ${ }^{8}$

\subsection{Outras Características Estruturais relativas à Relação entre a Dinâmica Econômica e a Pobreza}

Segundo Freeman (2001), a performance macroeconômica não prediz bem a magnitude da mudança na pobreza, uma vez que outros fatores estruturais intervêm entre a performance econômica agregada e a proporção de famílias ou indivíduos que estão abaixo da linha de pobreza. Esses fatores estruturais, que contribuem para explicar os padrões divergentes da relação crescimento e pobreza ao longo dos anos, são os aspectos demográficos, as políticas do governo e as especificidades do mercado de trabalho.

Os fatores demográficos podem afetar o perfil distributivo da renda e a taxa de pobreza de forma direta e indireta. O efeito direto é representado por alterações no tamanho e na estrutura etária da população resultando em modificações na razão de dependência das famílias já que o tamanho relativo da força de trabalho e o número de dependentes se altera e, portanto, seu nível de pobreza. Com relação aos efeitos indiretos, mudanças na taxa de crescimento da população e em sua estrutura etária podem implicar mudanças na oferta de trabalho e na taxa de poupança, consequentemente influenciando, de algum modo, o nível de salários e a taxa de juros. Sendo essas variáveis macroeconômicas importantes para a determinação da renda familiar, o efeito indireto das mudanças demográficas sobre a distribuição da renda e a pobreza ocorre, então, em função da relação entre as alterações demográficas e a oferta de trabalho, a taxa de poupança, o nível de salário e a taxa de juros.

As políticas públicas afetam as inter-relações econômicas de várias formas. Podem afetar as inter-relações entre o crescimento econômico e a pobreza, assim como o impacto do desemprego sobre a pobreza. Assim, as políticas macroeconômicas que têm a redução da taxa de pobreza como um de seus objetivos centrais, ao invés de restritivas, são caracterizadas pela promoção do crescimento econômico contínuo, sustentado e equilibrado e pela distribuição dos frutos desse crescimento. Ainda, considerando os importantes efeitos negativos que as recessões exercem sobre os mais pobres tanto no curto quanto no longo prazo, uma estratégia de crescimento voltada para o combate à pobreza deve ser sustentada por políticas que minimizem as flutuações na atividade econômica. Vale dizer, polí-ticas macroeconômicas com perfil anticíclico e dotadas de instrumentos capazes de reduzir as vulnerabilidades da economia frente às crises.

8 Para uma descrição detalha dos principais programas de transferência de renda executados atualmente pelo governo federal além do BPC, ver Soares et al. (2006). 
Importante, também, que o sistema econômico possua instrumentos que protejam os mais pobres nos momentos de maiores dificuldades. Sabemos que muitas das crises econômicas enfrentadas pelos países periféricos são inevitáveis, principalmente as crises externas. No entanto, dada a inserção dessas economias na atividade econômica mundial, os efeitos negativos tendem a ser sentidos de forma mais intensa nas economias dependentes. Nesse sentido, construir mecanismos de proteção representa mais que uma estratégia de combate à pobreza, representa uma consistente estratégia de crescimento sustentado e equilibrado no longo prazo. Aqui podemos observar a relevância dos programas de transferência direta de renda como uma importante ferramenta de política pública de cunho social. ${ }^{9}$ Vale ressaltar, no entanto, que essas políticas não apenas representam um mecanismo de proteção frente a crises econômicas, mas uma estratégia permanente de combate à pobreza. Ponderando os demais aspectos abordados, o fator estrutural mais importante para entender as mudanças da relação entre crescimento econômico e pobreza ao longo do tempo e verificar a validade da analogia com a maré alta é o mercado de trabalho. ${ }^{10}$ Cerca de $75 \%$ da renda familiar provém da renda do trabalho e, mesmo as famílias mais pobres, para as quais as transferências governamentais são relativamente mais importantes, dependem mais da renda do trabalho do que de outra fonte (IPEA, 2006). Dessa forma, a dinâmica dos salários reais é um dos fatores mais importantes para entender o impacto da dinâmica da economia sobre a pobreza.

Contudo, uma análise agregada da dinâmica dos salários reais impossibilita perceber uma série de fatores que, em conjunto, determinam a desigualdade salarial. Ou seja, a análise em termos agregados pode levar a interpretações equivocadas com relação ao cenário econômico observado pela população. A desigualdade salarial, assim, é um aspecto fundamental para entender e avaliar os impactos do crescimento econômico sobre o padrão de vida da população. ${ }^{11}$

9 É importante definir o que consideramos aqui como política social. De acordo com Cardoso Jr. e Jaccoud (2005) as políticas sociais representam um conjunto de programas destinados a reconhecer e proporcionar à população condições básicas de vida. Para a definição de condições básicas nesse aspecto, além de bens e serviços, leva-se em consideração a condição de cidadania, ou seja, as políticas sociais são medidas tomadas tendo como objetivo proporcionar aos indivíduos condições de serem cidadãos com direitos, e também deveres, de participarem do meio social do qual fazem parte.

10 Os comportamentos do emprego, dos salários e da renda real ao longo dos ciclos econômicos são os mais estudados na literatura. As evidências apontam para um padrão fortemente pró-cíclico do emprego e das horas trabalhadas. Trabalhadores menos qualificados tendem a encontrar postos de trabalho e a trabalhar jornadas mais longas. Já com relação aos salários reais, esses parecem ser apenas moderadamente pró-cíclicos. Para uma ampla revisão dessa literatura ver: Hines et al. (2001). Para um trabalho empírico, ver Blank (1989).

11 Quando a distribuição de rendimentos é estável e os salários reais aumentam, o crescimento diminui as taxas de pobreza. Em um período de crescente desigualdade salarial, os efeitos do crescimento sobre a pobreza podem ser compensados pelo aumento da desigualdade de renda advinda do trabalho (ROCHA, 2000; BARROS et al., 2000a). 
Nesse sentido, as especificidades de uma economia subdesenvolvida relacionadas à desigualdade de rendimentos advindos do trabalho são fatores-chave. É preciso ter em conta que as desigualdades de rendimentos do trabalho são produzidas e reproduzidas nessas economias, principalmente, pelas estruturas sociais - fundamentalmente pelas diferenças de oportunidades de capacitação profissional ${ }^{12}-\mathrm{em}$ conjunto com a forma de inserção dessas na divisão internacional do trabalho. Assim sendo, os resultados apresentados pelo mercado de trabalho são a representação, em termos monetários, da heterogeneidade social que forma um sistema econômico subdesenvolvido (RAMOS; VIEIRA, 2001).

A grande segmentação do mercado de trabalho, à parte a segmentação intrínseca relacionada ao processo produtivo, é reflexo de um sistema produtivo "incompleto" no sentido de não possuir uma cadeia produtiva integrada e relacionada tanto ao padrão tecnológico quanto à qualificação da mão de obra internamente disponível. ${ }^{13}$ As disparidades regionais desempenham, também, um importante papel. Observando o caso brasileiro, de acordo com IPEA (2006), em 2004 a remuneração dos trabalhadores de São Paulo era 60\% maior do que a dos trabalhadores de Pernambuco com idênticas características produtivas e a mesma inserção no mercado de trabalho. Além disso, há ainda disparidades intrarregionais importantes; observamos consideráveis diferenças de rendimento entre trabalhadores localizados nas capitais e outros localizados em municípios médios e pequenos no interior dos estados. Ademais, é importante ter em conta aqui, as disparidades salariais relacionadas às áreas urbana e rural. ${ }^{14}$

Outra fonte de geração de desigualdade de rendimentos é a discriminação, tanto por raça quanto por gênero. Em que pese o fato dessas formas de discriminação não serem peculiaridades do mercado de trabalho dos países subdesenvolvidos, seguramente é nestes países que o peso dessas segregações na pobreza é maior. No Brasil, conforme IPEA (2006), em 2004, homens com as mesmas características observáveis que as mulheres recebiam em média salários $70 \%$ mais al-

12 Merecem destaque tanto o efeito da desigualdade educacional, que embora tenha diminuído em termos quantitativos nos últimos anos, continua sendo determinante para a desigualdade de rendimentos quanto o efeito da experiência profissional, que apesar de estar intimamente relacionada ao exercício da profissão, em um sentido mais amplo é também relacionada ao nível educacional (cursos profissionalizantes, treinamentos, cursos de línguas, etc.).

13 A transnacionalização da produção transformou os países subdesenvolvidos em meros montadores, ficando os países centrais com as atividades de desenvolvimento das novas tecnologias. Assim, a inserção dos países periféricos nessa divisão internacional do trabalho os coloca em situação de plena dependência externa, sendo seu sistema produtivo subordinado e controlado pelos sistemas econômicos centrais. Esse é um dos pontos centrais para a construção da Teoria do Subdesenvolvimento Cepalina. Para uma ampla discussão dessa questão, ver Rodriguez (1981).

14 De acordo com IPEA (2006) em 2004, a remuneração de trabalhadores nas regiões metropolitanas era quase $20 \%$ superior à de trabalhadores com características e ocupações similares nos pequenos municípios do interior. Com relação aos trabalhadores urbanos, estes recebiam uma remuneração quase $10 \%$ acima dos trabalhadores rurais com idênticas características observáveis em postos de trabalho similares e com as mesmas características produtivas. 
tos. Já com relação à discriminação por raça, em 2004, em média, um indivíduo branco com características observáveis idênticas à de um indivíduo negro auferia uma remuneração 30\% maior.

Outra característica estrutural do mercado de trabalho dos países subdesenvolvidos intimamente ligada à desigualdade de rendimentos é a informalidade ${ }^{15}$. As características da atividade informal, relacionadas à ausência de regulamentação, concedem uma elevada flexibilidade ao mercado de trabalho, provocando uma alta rotatividade de trabalhadores tendo como consequências: postos de trabalho de baixa qualidade e insuficiente volume de investimentos em tecnologia e/ ou em capacitação profissional. De acordo com Cardoso Júnior (1999), é característica da atividade informal apresentar trabalhadores que se movem intensamente por ocupações distintas sem perspectivas de ascensão profissional nem salarial. Outro ponto chave para entender e evidenciar a relação dessa característica estrutural com a pobreza é a ausência ou precariedade de mecanismos de proteção social para trabalhadores informais.

Por fim, mas não menos relevante, considerando a importância da renda do trabalho para a relação entre a dinâmica da economia e a pobreza, uma análise sobre o desemprego é fundamental. Basicamente, para nossos objetivos, desemprego significa ausência de renda do trabalho, sendo então um aspecto central para a determinação do bem estar da população. Dentro dessa perspectiva, devemos considerar que, em momentos de baixo crescimento econômico, e, mais severamente, em momentos de crise, observa-se uma queda na demanda agregada, o que tende a reduzir a demanda por mão de obra no mercado de trabalho. Os ajustes no sistema produtivo, em geral, são feitos através de demissões e/ou reduções nas horas trabalhadas, principalmente, dos trabalhadores mais jovens e menos qualificados. Considerando que esses trabalhadores representam grande parte dos que recebem menores salários, esse processo reforça a condição de insuficiência de renda.

Além desse "canal de impacto individual", outra perspectiva importante é o "impacto social" provocado pelo desemprego. Seguindo Ferreira et al. (2000) o aumento do desemprego pode provocar rupturas na organização social - tensões religiosas e étnicas, aumento da violência e criminalidade, aumento da informalidade e do subemprego, etc. - que podem se transformar em situações de difícil solução, como observamos em muitos países atualmente.

15 Embora de difícil definição em termos práticos, devido à complexidade e à diversidade de atividades que integram essa categoria, em geral, é tratada como atividade informal atividades assalariadas desempenhadas fora do arcabouço institucional legalmente estabelecido pelo Estado - trabalhadores sem carteira assinada - somadas as atividades não assalariadas desenvolvidas por trabalhadores autônomos em que não há uma separação nítida entre a propriedade do empreendimento e a execução de suas atividades-fim (CARDOSO JUNIOR, 1999). 


\section{Ciclos Econômicos e Pobreza}

Os ciclos econômicos, definidos aqui como oscilações ${ }^{16}$ na taxa de crescimento do Produto Interno Bruto (PIB) afetam os indivíduos, as famílias, as firmas e o governo de maneira heterogênea. As oscilações na taxa de crescimento do PIB e, como consequência, as modificações no cenário econômico produzem efeitos diferenciados nos agentes econômicos, assim como podem produzir efeitos distintos em agentes de mesma natureza. Uma recessão não necessariamente desemprega trabalhadores de todos os setores, assim como nem todas as empresas terão seus volumes de vendas diminuídos. O mesmo vale para os períodos de crescimento (BLANK, 1989; NERI; THOMAS, 2000; AGENOR, 2001). Portanto, cabe buscar entender como os efeitos dos ciclos econômicos são sentidos pelos mais ricos, assim como pelos mais pobres.

Muitos países subdesenvolvidos enfrentaram choques econômicos nos anos 1980 e 1990, cujos impactos sobre o bem estar da população dependeu da natu-reza destes choques, das condições iniciais ao nível das famílias e das respostas polí-ticas dadas a eles (CUTLER; KATZ, 1993; AMADEO; NERI, 2000). Na década de 1980, particularmente para o caso do Brasil e dos países com elevada dívida externa da América Latina, a crise da dívida gerou um processo de estagnação nesses países com consequências danosas sobre renda, produto, emprego e preços (BAUMANN, 2000; STALLINGS; PERES, 2002). Na década de 1990, uma nova onda de crises, desta vez relacionadas aos efeitos negativos das reformas estruturais de primeira geração ${ }^{17}$ colocou-se como importante obstáculo frente à estratégia de crescimento dos países subdesenvolvidos. Merecem destaque o caso do México (1995), Sudeste da Ásia (1997/8), Rússia (1998) e Brasil (1999).

A literatura nos mostra que as crises dos anos 1980 e dos anos 1990 foram precedidas por elevados déficits em Conta Corrente. Em algum ponto, o receio da desvalorização levou a um estancamento dos fluxos de capitais que financiavam estes déficits, conduzindo à crise cambial. Frente à necessidade de ajuste, os países promoveram políticas fiscais e monetárias contracionistas, o que agravou a desaceleração econômica ou a recessão (Neri; Thomas, 2000) ${ }^{18}$. Assim, os impactos sobre a economia variaram dependendo do grau de exposição do sistema financeiro aos empréstimos em moedas estrangeiras, bem como da rigidez no mercado

16 Importante ressaltar que para essa definição de ciclo econômico não se assume um valor de equilíbrio ou uma taxa de crescimento de equilíbrio para a constatação das flutuações. Apenas considera-se a trajetória temporal da série. Uma vez que essa trajetória é marcada por variações na taxa de crescimento, essas variações, aqui, caracterizam o ciclo econômico.

17 Liberalização das importações, liberalização do sistema financeiro doméstico, abertura da Conta de Capitais do Balanço de Pagamentos, privatização e reforma tributária. Para uma descrição e uma análise dessas reformas ver: Stallings e Peres (2002).

18 A esse respeito ver Amadeo e Neri (2000), Bresser-Pereira e Nakano (2002), Ferreira et al. (2000) e Lustig (2000). 
de trabalho que pode diminuir o fluxo de recursos produtivos entre os setores. As respostas de política econômica acabaram levando à depreciação real da moeda, redução da demanda agregada e declínio dos padrões de vida de muitos grupos de pessoas - quase invariavelmente incluindo os mais pobres - por algum período de tempo (CUTLER; KATZ, 1993; DOLLAR; KRAAY, 2002; STALLINGS; PERES, 2002; ARESTIS, 2004). ${ }^{19}$

Para nossos objetivos, devemos ressaltar que, em geral, os pobres são os que mais sofrem com as oscilações macroeconômicas e principalmente com as recessões (LUSTIG, 2000; AGENOR, 2001). Isto porque, diante de um cenário macroeconômico instável, os pobres são os que menos possuem alternativas para evitar os efeitos negativos de uma desaceleração do PIB ou recessão, pois não possuem bens ou ativos financeiros que possam se constituir em reserva para períodos difíceis. Ainda, devido essa carência relativa em termos de ativos, frequentemente encontram dificuldades de acesso a crédito em bancos ou instituições financeiras (ARESTIS, 2004).

Como os mais pobres tendem a apresentar menor produtividade e menores níveis de escolaridade, têm menor mobilidade considerando tanto setores produtivos quanto regiões. Assim, enfrentam maiores dificuldades para mudarem de emprego, o que pode representar perda de boas oportunidades de trabalho. Do mesmo modo, possuem maiores limitações de acesso aos benefícios dos programas de seguro social, dada a constituição destes programas, uma vez que grande parte trabalha no setor informal (FERREIRA et al. 2000; CARDOSO; JACCOUD, 2005). Por fim, durante as crises, as despesas públicas tendem a sofrer cortes; uma vez que a organização e a força política dos mais pobres são menores, os programas de transferência, em geral, são os que sofrem os maiores cortes (CASTRO; CARDOSO JUNIOR, 2005) ${ }^{20}$.

Merece destaque, além do impacto direto das flutuações e das crises econômicas sobre os mais pobres, a resposta dada pelas famílias nos períodos de dificuldades (AGENOR, 2001; FREEMAN, 2001; BLANK; CARD, 2007). Em momentos econômicos ruins as famílias mudam seus padrões de consumo, realocam os níveis de produção entre os setores, modificam os padrões de oferta de trabalho - entrada dos filhos e das mulheres no mercado de trabalho, mudança para setor informal -, migram, etc. (FREEMAN, 2001; HINES; HOYNES; KRUEGER, 2001). A questão aqui é que, embora algumas dessas mudanças possam ter efeitos positivos

19 A medíocre performance macroeconômica nos anos 1980 e 1990 produziu um grande impacto sobre a pobreza e a desigualdade, embora poucas estimativas deste impacto estão disponíveis no Brasil. Para uma discussão a esse respeito ver: Barros et al. (2000a), Barros, Neri e Mendonça (1995) e Ferreira e Litchfield (1996).

20 Ademais, a construção e manutenção desses programas se constituem, em grande parte das vezes, de medidas emergenciais de caráter concentrado, ao passo que grande parte do orçamento público é marcada por despesas de caráter obrigatório sendo difícil e custoso implementar cortes nas outras áreas. 
de curto prazo, representam impactos negativos irreversíveis de longo prazo. Um exemplo é a restrição à educação dos jovens que têm de entrar para o mercado de trabalho, o que leva à redução da produtividade, reforçando as desigualdades existentes e criando uma pobreza persistente (FERREIRA et al., 2000).

De acordo com Lustig (2000) as crises macroeconômicas tendem a afetar a produtividade dos mais pobres através do aumento do custo de oportunidade da educação no curto prazo, da queda na qualidade da alimentação e nos gastos com saúde. Assim sendo, as políticas macroeconômicas orientadas somente a promover o crescimento econômico mostram-se insuficientes para combater a pobreza. Diminuir a vulnerabilidade da economia a choques e principalmente minimizar os efeitos das recessões, evitando grandes quedas no padrão de vida da população mais pobre é fundamental (FERREIRA et al. 2000; NERI; THOMAS, 2000). Mais ainda, evitar que as políticas restritivas, que em geral são implementadas em momentos de recessão, aprofundem os efeitos negativos do momento econômico ruim são importantes características de uma agenda macroeconômica que tem no combate à pobreza um objetivo central.

\section{Método}

Em virtude da heterogeneidade regional que apresenta o Brasil, a análise das relações entre o desempenho macroeconômico e a taxa de pobreza será feita a nível estadual. Isto porque consideramos que a pobreza varia sobremaneira entre os estados, e uma análise que considera o país como um todo pode não captar essas diferenças regionais. Mais ainda, é importante ter em conta que a pobreza mudou diferentemente entre os estados, na medida em que as condições econômicas foram se alterando ao longo do período analisado ${ }^{21}$ (DINIZ, 2002; DINIZ; GONÇALVES, 2005; DINIZ; LEMOS, 1996).

Para realizar esse exercício utilizaremos o seguinte modelo para dados em painel:

$$
y_{i t}=\beta_{0}+\beta_{1} X_{i t}+\beta_{2} Z_{i t}+\varepsilon_{i t}
$$

Em que:

$y_{i t}=$ taxa de pobreza estadual, que varia tanto entre os estados quanto com o tempo;

$X_{\text {it }}=$ conjunto de variáveis de interesse, que variam entre os estados e com o tempo;

21 Mesmo entendendo que a análise a nível estadual pode não considerar desigualdades intra-estado, a falta de disponibilidade de algumas informações municipais limita o escopo da análise nesse nível de desagregação. Isso reforça nossa opção pela análise no nível estadual. 
$Z_{\mathrm{it}}=$ conjunto de variáveis de controle, também apresentando características que variam entre os estados e com o tempo;

$\varepsilon_{i t}=$ termo de erro que é composto de uma parte que não varia no tempo e é específica a cada estado, representando os efeitos fixos não observados associados a cada estado, e outra que varia tanto no tempo quanto entre os estados. Assim, o termo de erro assume a seguinte forma: $\varepsilon_{i t}=u_{i}+e_{i t ;}$

$i=1,23, \ldots \ldots .26$ (estados);

$t=1981,1982, \ldots \ldots \ldots \ldots \ldots \ldots . . .2006$ (período).

O nosso ponto de partida para investigar como a dinâmica do sistema econômico afeta a taxa de pobreza estadual é analisar as relações entre a performance cíclica da economia e a taxa de pobreza. Para tanto, as variáveis-chave que serão utilizadas aqui como indicadores da atividade econômica, ou melhor, nosso conjunto $\mathrm{X}$ para esse exercício são: a taxa de atividade estadual, a taxa de desemprego estadual e a massa da renda familiar real ponderada pelo tamanho da população. ${ }^{22}$

Uma vez que o objetivo central desse exercício é avaliar as relações entre o comportamento cíclico da economia e a taxa de pobreza, um conjunto de variáveis será introduzido no modelo, tratadas como variáveis de controle (conjunto Z). Como é tratado na literatura, a razão para a introdução desse conjunto de variáveis de controle é tentar captar os "efeitos puros" das variáveis de interesse. De outra forma, evitar que possíveis relações não determinadas pelas variáveis de interesse sejam atribuídas a elas, ou seja, é uma tentativa de minimizar as possíveis distorções nas estimativas causadas pela omissão de variáveis e/ou pela má especificação do modelo.

Nessa categoria se encontram variáveis que representam características demográficas (CD), variáveis que representam características socioeconômicas (SE) e também uma variável de tendência para controlar o efeito temporal no comportamento da taxa de pobreza no período. A escolha das variáveis que compõem nosso conjunto de variáveis de controle, como pode ser observado, é função direta das considerações feitas na discussão teórica sobre os determinantes e condi-cionantes das relações entre a pobreza e o desempenho do sistema econômico. Elas buscam caracterizar tanto fatores conjunturais quanto estruturais do meio no qual o indivíduo esta inserido, como também expressam, de forma agregada, impor-tantes características individuais que são fundamentais para a determinação da condição de pobreza.

Ademais, a inclusão dessas variáveis permite controlar os efeitos da composição da população intra e entre os estados e também ao longo do tempo. Adi-

22 Utilizamos esta variável como proxy para o PIB estadual já que não dispomos de informação para essa variável para todo o período de análise. 
cionalmente, as variáveis de controle foram incluídas como estratégia de identificação do efeito causal entre as variáveis utilizadas nas estimações.

O conjunto (CD) será composto pelas seguintes variáveis: média de anos de estudo, proporção de famílias chefiadas por mulheres, razão de dependência estadual (proporção de idosos e crianças em relação aos indivíduos em idade ativa), proporção de homens, um indicador de desigualdade educacional (razão entre a proporção de pessoas com mais de 12 anos de estudo e proporção com menos de 4 anos) e proporção de pessoas ocupadas nas seguintes categorias de ocupação: agricultura, atividades manuais, atividades de nível médio e atividades de nível superior. ${ }^{23}$

O outro conjunto de variáveis de controle, o conjunto socioeconômico (SE), será composto pelas variáveis: proporção de pessoas que vivem em áreas urbanas, proporção de pessoas que trabalham no setor informal, proporção de pessoas que trabalham em tempo integral e um índice de desigualdade de renda (coeficiente de Gini da renda familiar per capita real). ${ }^{24}$

\subsection{Fonte de Dados}

As informações relacionadas às características da população, tanto socioeconômicas quanto demográficas, assim como as informações referentes às especificidades estaduais, foram construídas a partir da Pesquisa Nacional por Amostra de Domicílios - PNAD - realizada pelo Instituto Brasileiro de Geografia e Estatística - IBGE -. Este é um sistema de pesquisas por amostra de domicílios que investiga diversas características sócio-econômicas como características gerais da população, educação, trabalho, rendimento e habitação; sendo esses considerados como temas básicos. Além destes, periodicamente são acrescentados outros tópicos, carac-terizados como suplementos em uma tentativa de adequar o questionário às transformações sociais que ocorrem ao longo do tempo. ${ }^{25}$

\subsection{Análise Descritiva das Variáveis}

Partindo das informações individuais disponibilizadas pelas PNADs e de acordo com a opção metodológica de agregação descrita, construíram-se as variáveis que constituem o banco de dados agregado a nível estadual. Assim, as variáveis expressam médias, taxas e proporções discriminadas por Unidades da Federação, inclusive o Distrito federal. ${ }^{26}$ De posse das informações disponibili-

23 Para a classificação dessas categorias seguimos a classificação da PNAD.

24 A partir dos microdados das PNADs, podemos construir uma série temporal com dados nacionais e uma série temporal acumulada de cross-sections com dados estaduais.

25 Na década de 1970, foi investigado o tema da migração; na de 1980, os temas saúde, mão de obra e previdência social; e na década de 1990, os temas foram a migração, a fecundidade e a nupcialidade. Na de 2000 educação, saúde e renda.

26 Considerando que o estado de Tocantins foi criado após a Constituição de 1988, e tendo em conta 
zadas pelas PNADs, construíram-se séries históricas por Unidade da Federação para todas as variáveis que constituem o banco de dados; vale ressaltar que em virtude de modificações nos questionários da pesquisa, compatibilizações foram feitas no sentido de tornar as informações comparáveis ${ }^{27}$. Considerando o período de análise, inicialmente, não dispomos de informações para os anos de 1991, 1994 e 2000, anos que não houve PNAD. Assim, para preencher essas lacunas em nossa série temporal, utilizamos as informações dos dois anos anteriores e posteriores fazendo uma média ponderada desses e dando maior peso ao ano antecessor e sucessor ${ }^{28}$.

Utilizamos como variável dependente no nosso exercício econométrico a taxa de pobreza estadual (txpob) ${ }^{29}$. Inicialmente construímos uma linha de pobreza tendo com referência o valor monetário real de uma cesta de produtos alimentares capaz de suprir o mínimo de calorias diárias recomendada pela FAO (2100 calorias) sem considerar idade, sexo, ou qualquer outra característica. Essa cesta de produtos alimentares é fixa, porém diferenciada para as grandes regiões do país com base nos padrões alimentares dos domicílios de baixa renda (os $20 \%$ mais pobres na distribuição de renda) observados na Pesquisa do Orçamento Familiar (POF) de 1996. Dessa forma construímos uma linha de pobreza por estado, com base na renda dos indivíduos, ${ }^{30}$ e o número de indivíduos considerados pobres é determinado pela quantidade de pessoas cuja renda é menor do que o valor estabelecido pela linha de pobreza. Por conseguinte, a taxa de pobreza estadual é determinada pela proporção de indivíduos considerados pobres em relação ao total da população estadual ${ }^{31}$.

Vale ressaltar que, como a variável dependente é a proporção de indivíduos considerados pobres, não é possível utilizar somente características dos próprios pobres, pois isso desconsideraria a fundamental composição da popu-

o período de análise, as informações referentes a esse estado foram incorporadas às informações do Estado de Goiás.

27 As principais modificações, no nosso caso, ocorreram nas perguntas sobre a classificação das categorias de ocupação e sobre desemprego.

28 Os pesos foram atribuídos da seguinte forma: ao ano antecessor e ao ano sucessor foi imputado um valor de 0,35. Ou seja, no conjunto as informações desses anos correspondem a 0,7 da informação construída. Os outros dois anos receberam um valor de 0,15 cada.

29 Para a construção dessa taxa de pobreza utilizamos a metodologia desenvolvida por Rocha (1997). A opção por essa metodologia se deve ao fato dela possibilitar captar tanto as variações conjunturais relacionadas à determinação da renda das pessoas quanto às especificidades regionais presentes no Brasil. Ainda, é importante ressaltar que a escala dessa variável varia de 0 a 100. Os preços dos produtos alimentares utilizados na determinação dessa linha de pobreza diferem por estado e, dentro desses, para regiões metropolitanas para as quais se dispõe de informações na POF.

31 Os valores atribuídos às linhas de pobreza estaduais têm como referência o ano de 2006 e foram deflacionados pelo INPC de acordo com Corseul e Foguel (2002). Para uma explicação mais detalhada, ver: CORSEUIL, C. H.; FOGUEL, M. N. Uma sugestão de deflatores para rendas obtidas a partir de algumas pesquisas domiciliares do IBGE. Brasília, DF: IPEA, jul. 2002. (Texto para discussão, n. 897). 
lação da Unidade da Federação. Ou seja, o efeito composicional "viesaria" os resultados e haveria na construção das variáveis explicativas um viés de seleção para o próprio grupo - de pobres - o qual se busca explicar. Ademais, as características contextuais ao nível das unidades estaduais consideradas são cruciais para o entendimento da dinâmica da pobreza.

\subsubsection{Variáveis Independentes: Variáveis de Interesse e Variáveis de Controle}

No Quadro 1 mostramos o conjunto de variáveis que compõem o banco de dados. Em seguida, descrevem-se as variáveis justificando a presença das mesmas e evidenciando o que desejamos captar e controlar com a inclusão delas na estimação.

Quadro 1 - Conjunto de variáveis do banco de dados

\begin{tabular}{|c|c|c|}
\hline \multicolumn{3}{|c|}{ Variáveis de Interesse } \\
\hline $\begin{array}{c}\text { Comportamento cíclico } \\
\text { da economia }\end{array}$ & Descrição & Fonte \\
\hline txativ & Taxa de atividade por UF & PNAD \\
\hline txdesemp & Taxa de desemprego por UF & PNAD \\
\hline rendfamrtpop & $\begin{array}{l}\text { Massa da renda familiar real por UF } \\
\text { ponderada pelo tamanho da popula- } \\
\text { ção (proxy para o PIB estadual) }\end{array}$ & PNAD \\
\hline \multicolumn{3}{|c|}{ Variáveis de controle } \\
\hline $\begin{array}{c}\text { Características } \\
\text { demográficas }\end{array}$ & Descrição & Fonte \\
\hline anosest & Média de anos de estudo por UF & PNAD \\
\hline chefem & $\begin{array}{l}\text { Proporção de famílias chefiadas por } \\
\text { mulheres por UF }\end{array}$ & PNAD \\
\hline homem & Proporção de homens por UF & PNAD \\
\hline razdep & Razão de dependência na UF & PNAD \\
\hline deseduc & Desigualdade educacional por UF & PNAD \\
\hline agri & $\begin{array}{l}\text { Proporção das pessoas que trabalham } \\
\text { na agricultura por UF }\end{array}$ & PNAD \\
\hline sup & $\begin{array}{l}\text { Proporção das pessoas que trabalham } \\
\text { em atividades de nível superior por UF }\end{array}$ & PNAD \\
\hline
\end{tabular}




\begin{tabular}{|c|c|c|}
\hline \multicolumn{3}{|c|}{ Variáveis de controle } \\
\hline $\begin{array}{c}\text { Características } \\
\text { demográficas }\end{array}$ & Descrição & Fonte \\
\hline medio & $\begin{array}{c}\text { Proporção das pessoas que trabalham } \\
\text { em atividades de nível médio por UF }\end{array}$ & PNAD \\
\hline manual & $\begin{array}{c}\text { Proporção das pessoas que trabalham } \\
\text { em atividades manuais por UF }\end{array}$ & PNAD \\
\hline $\begin{array}{c}\text { Características } \\
\text { socioeconômicas }\end{array}$ & Descrição & PNAnte \\
\hline urb & $\begin{array}{c}\text { Proporção de pessoas que vivem no } \\
\text { meio urbano por UF }\end{array}$ & PNAD \\
\hline informal & $\begin{array}{c}\text { Proporção de pessoas que trabalham } \\
\text { no setor informal por UF }\end{array}$ & PNAD \\
\hline integral & $\begin{array}{c}\text { Proporção de pessoas que trabalham } \\
\text { em horário integral por UF }\end{array}$ & PNAD \\
\hline gini_k & Índice de Gini da renda por UF & PNAD \\
\hline
\end{tabular}

Fonte: Elaboração própria.

a) txativ: definida como a relação entre o número de pessoas economicamente ativas e o número de pessoas em idade ativa em um determinado período de referência, ou seja, é a relação entre a PEA e a PIA. Representa um indicador fundamental para nossos objetivos na medida em que nos permite captar os efeitos da dinâmica do sistema econômico sobre a PEA e, consequentemente, sobre a taxa de pobreza;

b) txdesemp: definida como o percentual de pessoas desocupadas em relação às pessoas economicamente ativas; é também fundamental, uma vez que, além de captar os efeitos cíclicos da economia, permite-nos considerar, de forma mais direta, o efeito da renda do trabalho sobre a taxa de pobreza;

c) remdfamrtpop: definida como o somatório das rendas do trabalho de todos os membros da família em termos reais, tendo o ano de 2006 como referência, agregadas por estado. Esse indicador, utilizado aqui como proxy para o PIB estadual, permite captar os efeitos da atividade econômica sobre a taxa de pobreza de uma forma mais agregada. ${ }^{32}$

d) anosest: é largamente utilizado na literatura econômica o papel da educação na determinação dos rendimentos bem como para a inserção dos indivíduos na sociedade. Assim, essa variável de

32 Considerando que as duas variáveis anteriores evidenciam efeitos mais concentrados sobre os indivíduos, esse indicador de renda estadual possibilita captar, além dos efeitos dos ciclos, efeitos relacionados ao meio social, político e econômico no qual esses indivíduos estão inseridos. 
média de anos de estudo tem o objetivo de captar, tanto os efeitos da educação sobre a pobreza via mercado de trabalho, como também a capacidade do individuo de exercer seus direitos e deveres de cidadania;

e) chefem: ao longo dos anos tem crescido o número de famílias chefiadas por mulheres e essas famílias tendem a apresentar taxas de pobreza elevadas. Assim, a inclusão dessa variável, de proporção de mulheres entre os chefes de família, procura controlar os efeitos dessa mudança demográfica sobre a taxa de pobreza estadual;

f) homem: representa a proporção de homens; a inclusão dessa variável tem como propósito controlar qualquer tipo de efeito relacionado à proporção diferenciada da população por sexo na determinação da taxa de pobreza;

g) razdep: o controle do efeito da razão de dependência - definida como a razão entre os indivíduos de zero a nove anos somados aos indivíduos maiores de 65 anos em relação aos indivíduos que possuem idade entre 10 e 64 anos - sobre a pobreza apresenta, aqui, duas faces que, de certa forma, caminham em direções opostas: uma mais direta, relacionada ao fato de que, quanto maior a razão de dependência maior a incidência de pobreza, ou seja, um grande número de dependentes tende a levar a uma insuficiência de renda para suprir as necessidades básicas. Contudo, esse aspecto de dependência apresenta um outro lado, que é o efeito da renda advinda da aposentadoria;33

h) deseduc: a razão para a inclusão de uma variável que capta o efeito da desigualdade educacional - definida como a razão entre os indivíduos que possuem 12 ou mais anos de estudo em relação aos que possuem quatro ou menos anos de estudo - sobre a pobreza é considerar possíveis efeitos da educação sobre a taxa de pobreza não captados por uma medida agregada como a média de anos de estudo;

i) variáveis de ocupação: dadas as características estruturais presentes no mercado de trabalho, a inclusão desse conjunto de variáveis busca controlar os efeitos das desigualdades advindas do mercado de trabalho relacionadas à ocupação como produtividade, rendimento, inserção social;

j) urb: a inclusão dessa variável possui dois objetivos: o primeiro é relacionado a uma opção metodológica, já que a PNAD, para os anos da década de 1980, não oferece informações para o meio

33 Esse efeito tende a ser menor em uma análise familiar, uma vez que o número de idosos em uma família é, em geral, pequeno; mas, como aqui estamos operando com um nível de agregação mais elevado, o efeito aposentadoria é relevante e reforçado pela tendência de envelhecimento da população, mesmo porque o valor de um salário mínimo, piso para os benefícios, é bem acima de qualquer linha de pobreza. 
rural dos estados que constituem a região norte. ${ }^{34} \mathrm{O}$ outro é relacionado ao aspecto tratado na literatura de que os indivíduos que vivem no meio urbano são os mais afetados pelas oscilações no cenário econômico;

k) informal: esta categoria é definida aqui de acordo com Cardoso Júnior (1999). ${ }^{35}$ Controlar os efeitos dessa característica estrutural do mercado de trabalho brasileiro é fundamental já que, como ressaltado, grande parte da PEA se encontra nessa categoria de inserção e a atividade informal apresenta, em geral, rendimentos menores, além de não possuir um sistema de seguridade social. Assim, espera-se que a incidência da pobreza sobre os indivíduos que exercem atividades informais tende a ser maior, além desses serem mais vulneráveis as condições econômicas;

1) integral: integram essa categoria pessoas que trabalham mais do que 30 horas semanais. Indivíduos que trabalham em tempo integral tendem a receber maiores salários; ainda, a literatura mostra que em momentos de situação econômica favorável os indivíduos tendem a procurar trabalhos de tempo integral e em situações adversas, as empresas, ao invés de demitir os funcionários, diminuem o horário de trabalho, já que o custo de demitir um empregado é muito alto. Assim, controlar o efeito dessa característica do mercado de trabalho é importante, pois ela tem impacto direto na determinação da renda;

m) gini_k: é fato consolidado na literatura que a desigualdade de renda é um dos pontos principais na determinação da taxa de pobreza. Assim, o objetivo ao incluir essa variável é controlar o efeito da desigualdade de renda sobre a taxa de pobreza;

n) dummies de período: inserimos três dummies de período - 1986, 1994 e 2002 - com o objetivo de captar e controlar os efeitos sobre a taxa de pobreza de eventos ocorridos nesses anos que mudaram o padrão de comportamento da taxa de pobreza no país. ${ }^{36}$ Ainda, incluímos uma variável de tendência numa tentativa de controlar o efeito temporal sobre a trajetória da taxa de pobreza no período de análise.

34 Assim, não considerar essa deficiência na construção das estimativas certamente representa um erro grave que implicaria em resultados sem validade.

35 A categoria informal é formada pelos trabalhadores sem carteira assinada somados aos trabalhadores autônomos que desenvolvem atividades não assalariadas em que não há uma separação nítida entre a propriedade do empreendimento e a execução de suas atividades-fim.

36 Em 1986 o Plano cruzado promoveu um forte crescimento na renda ao proporcionar um elevado aumento no salário real. Em 1994, após um período de altas taxas de inflação, o Plano Real promoveu a estabilização da economia, o que limitou o efeito negativo da escalada dos preços sobre a renda dos mais pobres. Por fim, a partir de 2002 observamos um fortalecimento os programas de transferência de direta de renda por parte do governo federal, com considerável importância para os mais pobres. Tendo em conta o intervalo entre os eventos ocorridos e os efeitos por eles desencadeados, a variável dummy para o ano de 1984 assume valor 1 a partir do próprio ano de 1984. Já as demais variáveis assumem valor 1 a partir dos anos subsequentes aos eventos que desejamos controlar. 


\section{Resultados}

Como podemos observar na Tabela 1 apenas as variáveis taxa de atividade (txativ) e taxa de desemprego (txdesemp) foram utilizadas como indicadores da atividade econômica nessa primeira estimação, ao passo que a variável massa da renda familiar real ponderada pelo tamanho da população (rendfamrtpop) foi utilizada para o modelo demonstrado na Tabela 2 . As razões para essa separação são de ordem técnica, bem como uma opção metodológica.

Considerando a questão técnica, a inclusão das três variáveis em um mesmo modelo poderia resultar em estimativas viesadas em virtude da alta correlação entre elas. Outro aspecto é relacionado à especificação da variável dependente nos dois modelos: enquanto na estimação apresentada na Tabela 1 usamos a taxa de pobreza, no exercício demonstrado na Tabela 2 a variável dependente é o logaritmo da taxa de pobreza. A opção metodológica pela estimação em separado está diretamente relacionada às formas funcionais das estimações, mais especificamente, às diferentes relações que os diferentes modelos conseguem captar. Considerando a natureza dos dados e as relações entre as variáveis, entendemos que estimar as relações entre a dinâmica da economia e a taxa de pobreza em dois modelos separados e com fórmulas funcionais distintas nos proporciona resultados que permitem uma análise mais ampla; ou melhor, resultados que nos possibilitam observar as mesmas relações por ângulos diferentes, explorando diferentes perspectivas. ${ }^{37}$

O modelo 1 é apresentado na Tabela 1 e, de acordo com os testes estatísticos realizados, concentraremos nossa análise nos resultados apresentados pelo modelo de efeitos fixos (FE). Isso porque os resultados dos testes (F) e (LM) rejeitam a hipótese de que não há variabilidade no termo de intercepto; isto é, de que o modelo MQO é o mais adequado. Assim sendo, os modelos de painel podem ser considerados os mais apropriados para a estimação de acordo com a estrutura de dados de que dispomos. Ainda, observando o resultado do Teste de Hausmann, podemos aceitar a hipótese de que o modelo (FE) apresenta os estimadores mais consistentes e eficientes. ${ }^{38}$

37 Com relação aos resultados apresentados, mostramos os números para o modelo de Mínimos Quadrados Ordinários (MQO) somente para evidenciar as vantagens de se utilizar a técnica de estimação de dados em painel e porque é através dos resultados da estimativa por MQO que realizamos os dois testes de ajustamento para a utilização dos modelos de painel, o teste (F) e o teste (LM). Já com relação aos resultados das estimativas em painel, mostramos tanto os resultados para o método de efeitos fixos (FE) quanto para o método de efeitos aleatórios (RE). Contudo, nossa análise se concentrará no modelo definido como o mais apropriado de acordo com o Teste de Hausmann.

38 Esse resultado corrobora nossas expectativas, uma vez que entendemos que existem fatores não observáveis ligados às especificidades estaduais como aspectos históricos, culturais e sociais, que não variam com o tempo, e que são importantes para a determinação dos efeitos da atividade econômica sobre a taxa de pobreza estadual; isto é, esses efeitos não observáveis que influenciam 
Tabela 1 - Taxa de pobreza como função da taxa de desemprego e da taxa de atividade

\begin{tabular}{|c|c|c|c|c|c|c|}
\hline \multirow{2}{*}{ txpob } & \multicolumn{2}{|c|}{ MQO } & \multicolumn{2}{|c|}{$\mathbf{F E}$} & \multicolumn{2}{|c|}{$\mathbf{R E}$} \\
\hline & Coef. & $P>t$ & Coef. & $P>t$ & Coef. & $\mathbf{P}>\mathbf{z}$ \\
\hline txdesemp & 0,20 & 0,033 & 0,26 & 0,015 & 0,22 & 0,021 \\
\hline txativ & $-0,73$ & 0,000 & $-0,30$ & 0,049 & $-0,67$ & 0,000 \\
\hline urb & 14,56 & 0,000 & 23,40 & 0,000 & 14,71 & 0,001 \\
\hline informal & 21,76 & 0,000 & 6,82 & 0,052 & 16,94 & 0,001 \\
\hline integral & $-7,07$ & 0,031 & $-0,17$ & 0,080 & $-7,96$ & 0,026 \\
\hline gini_k & 76,04 & 0,000 & 103,08 & 0,000 & 83,47 & 0,000 \\
\hline homem & $-109,95$ & 0,001 & $-33,50$ & 0,037 & $-77,64$ & 0,024 \\
\hline anosest & $-12,12$ & 0,000 & $-11,12$ & 0,000 & $-12,82$ & 0,000 \\
\hline chefem & 51,87 & 0,000 & 34,87 & 0,026 & 52,25 & 0,000 \\
\hline razdep & 3,46 & 0,693 & $-19,74$ & 0,113 & $-3,53$ & 0,681 \\
\hline deseduc & 26,18 & 0,000 & 26,73 & 0,000 & 27,78 & 0,000 \\
\hline agri & $-19,10$ & 0,591 & 20,74 & 0,644 & $-21,67$ & 0,565 \\
\hline sup & $-53,56$ & 0,148 & $-10,91$ & 0,808 & $-54,27$ & 0,159 \\
\hline medio & $-10,10$ & 0,774 & 29,04 & 0,519 & $-12,61$ & 0,737 \\
\hline manual & 13,53 & 0,680 & 38,89 & 0,392 & 7,20 & 0,838 \\
\hline ano & 1,58 & 0,000 & 1,76 & 0,000 & 1,68 & 0,000 \\
\hline d1986 & $-4,35$ & 0,006 & $-8,11$ & 0,000 & $-5,25$ & 0,001 \\
\hline d1994 & $-17,61$ & 0,000 & $-19,66$ & 0,000 & $-18,28$ & 0,000 \\
\hline $\mathrm{d} 2002$ & $-19,73$ & 0,000 & $-23,96$ & 0,000 & $-20,79$ & 0,000 \\
\hline intercepto & $-3000,46$ & 0,000 & $-3456,00$ & 0,000 & $-3217,78$ & 0,000 \\
\hline Número de Obs. & \multicolumn{2}{|c|}{676} & \multicolumn{2}{|c|}{676} & \multicolumn{2}{|c|}{676} \\
\hline $\mathrm{R}^{2}$ & \multicolumn{2}{|c|}{0,83} & \multicolumn{2}{|c|}{0,78} & \multicolumn{2}{|c|}{0,83} \\
\hline LM & \multicolumn{2}{|c|}{135,20} & Prob $>X^{2}$ & 0 & & \\
\hline Hausmann & \multicolumn{2}{|c|}{45,58} & Prob $>X^{2}$ & 0 & & \\
\hline Teste $F_{(19,631)}$ & \multicolumn{2}{|c|}{35,32} & Prob $>F$ & 0 & & \\
\hline
\end{tabular}

Fonte: Elaboração própria a partir da PNAD 1981-2006.

Como podemos observar, as variáveis que representam os ciclos se mostraram bastante significativas e com os sinais esperados. Ainda, considerando a magni-

a determinação da taxa de pobreza estadual apresentam alguma correlação com as variáveis explicativas implicando que as informações não sejam independentes distribuídas ao longo do tempo. 
tude dos resultados, os efeitos da taxa de atividade sobre a taxa de pobreza são maiores do que os efeitos da taxa de desemprego.

O considerável efeito negativo da taxa de atividade sobre a taxa de pobreza estadual reflete, mais do que uma condição de estar ou não empregado, a relevância de ser considerado como economicamente ativo. Independentemente da definição de pobreza utilizada, a determinação da condição social do indivíduo é função direta do meio no qual ele está inserido. Considerando que a dinâmica social é um processo circular, em que as relações entre os fatores sociais nem sempre são diretas e que a interação desses fatores se dá ao longo do tempo, estar inserido no grupo dos economicamente ativos tem uma importância não só de curto, mas também de longo prazo na determinação da condição de pobreza. Nesse sentido, fazer parte da População Economicamente Ativa (PEA) ${ }^{39}$ abre uma gama de possibilidades para que o indivíduo consiga auferir os recursos necessários para se situar acima da linha de pobreza. Fica claro, assim, que um aumento na taxa de atividade reduz a taxa de pobreza. Mas essa relação deve ser analisada com cuidado, já que os desempregados entram na contagem dos economicamente ativos ${ }^{40}$. Todavia, o inverso é verdadeiro e, sem ressalvas, uma queda na taxa de atividade aumenta a taxa de pobreza.

Com relação ao efeito positivo e significativo da taxa de desemprego sobre a taxa de pobreza, esse resultado, além de demonstrar os efeitos diretos da ausência de renda advinda do trabalho sobre a taxa de pobreza, ratificando a perspectiva de que a renda do trabalho é uma das principais fontes de renda mesmo para aqueles que recebem transferências diretas por parte do governo, mostra, também, que os períodos de recessão, nos quais a taxa de desemprego tende a aumentar, são acompanhados de aumento na taxa de pobreza estadual. Assim, uma questão central para a redução da taxa de pobreza é a capacidade da atividade econômica em gerar empregos. Ademais, dentro dessa perspectiva, é importante considerar a capacidade de manutenção dos empregos em períodos de crise. Mas, além de gerar e manter o nível de emprego é importante que o sistema econômico, ao empregar sua mão de obra, seja capaz de gerar renda e que essa renda seja distribuída da melhor forma possível. E esse é um dos principais desafios a serem enfrentados pela economia brasileira já que observamos um grande do

39 De acordo com a definição do IBGE, a População Economicamente Ativa (PEA) compreende o potencial de mão de obra com que pode contar o setor produtivo, isto é, a população ocupada e a população desocupada, assim definidas: População Ocupada: aquelas pessoas que, num determinado período de referência, trabalharam ou tinham trabalho, mas não trabalharam (por exemplo, pessoas em férias). As pessoas ocupadas são classificadas em: empregados, conta própria, empregadores e não remunerados; População Desocupada: aquelas pessoas que não tinham trabalho, num determinado período de referência, mas estavam dispostas a trabalhar, e que, para isso, tomaram alguma providência efetiva (consultando pessoas, jornais, etc.).

Os efeitos com relação ao desemprego serão tratados em seguida. 
número de trabalhadores empregados no setor informal e uma limitada capacidade de crescimento econômico.

Considerando o modelo 2 apresentado na Tabela 2, os resultado dos testes estatísticos nos conduzem para o mesmo caminho do exercício anterior. Assim, novamente, concentraremos nossa análise no modelo de efeitos fixos $(\mathrm{FE})^{41}$. Como podemos observar, a variável que representa a dinâmica da economia nesse modelo, logaritmo da massa de renda familiar real ponderado pelo tamanho da população (lrendfamrtpop), mostrou-se significativa e apresentou o sinal esperado. Mais ainda, ela evidencia a alta elasticidade da pobreza em função da renda. Especificamente, mantendo as demais condições sem alteração, um aumento de $1 \%$ na renda familiar real conduz a uma redução média de $1,07 \%$ na taxa de pobreza dos estados.

Aqui cabe uma comparação com os trabalhos citados que também realizaram a estimação das elasticidades renda-pobreza para os estados brasileiros. Barreto, Marinho e Soares (2003), Hoffmann (2005) e Tochetto et al. (2004) ${ }^{42}$ verificam uma variação considerável para os valores absolutos das elasticidades rendapobreza estaduais. Ademais, as elasticidades tendem a ser, em valores absolutos, maiores nas localidades que apresentam maior renda e menores nas localidades que apresentam maiores índices de desigualdade de renda. Considerando valores, Hoffmann (2005) apresenta uma estimativa agregada para o Brasil: (-0,84); esse valor, em termos absolutos, é próximo, porém menor, ao encontrado aqui.

Fazendo um paralelo com a literatura internacional, encontramos poucos trabalhos que tratam da estimação da elasticidade renda-pobreza para o Brasil, mas em nenhum desses casos, observamos a estimação para os estados brasileiros. A grande maioria desses trabalhos tem como foco a comparação das elasticidades renda-pobreza entre países e/ou continentes. Mesmo considerando que as variações no tratamento das variáveis, no método de estimação e no período avaliado são decisivos para os resultados encontrados, entendemos ser possível uma comparação no sentido de evidenciar os pontos ressaltados nesse trabalho, em especial a inclusão de um conjunto de variáveis de controle para a estimação da elasticidade-pobreza, uma vez que a maioria dos trabalhos encontrados utilizam como variáveis dependentes apenas o logarítmo da taxa de crescimento do Produto Interno Bruto e o logaritmo do Índice de Gini.

Analisando os resultados, Bourguignon (2002), avaliando o período entre 1985 e 2006, encontra uma elasticidade renda-probreza para o Brasil próxima de (-2). Importante ressaltar que nesse trabalho o autor utiliza, para a determinação

41 Vale ressaltar que esses resultados, indicando o modelo FE, novamente corroboram nossas expectativas com relação à correlação entre os efeitos não observáveis e as variáveis explicativas na determinação da taxa de pobreza estadual.

42 Uma tabela comparativa contendo os resultados encontrados nesse trabalho assim como os encontrados nos demais trabalhos citados encontra-se em anexo. 
da linha de pobreza, o parâmetro "U\$ 1,00 por dia" corrigido pela Paridade de Poder de Compra (PPC). Já Fosu (2010), usando como parâmetro para a definição da linha de pobreza a regra "U\$ 2,50 por dia" encontra, para o ano de 2007, uma estimativa para a elasticidade renda-pobreza no Brasil de $(-1,939)$. Ravallion (2009), ao comparar o padrão de redução da taxa de pobreza no Brasil, na China e na India, avaliando o período entre 1993 e 2005 e considerando a regra "U\$ 1,25 por dia" para a determinação da taxa de pobreza e também corrigindo pela (PPC), mas tendo como referência o ano de 2005, encontra um valor de $(-3,2)$ para a elasticidade renda-pobreza no Brasil. Por fim, Ferreira, Leite e Ravallion (2007) avaliando o período compreendido entre os anos de 1985 e 2004, e usando como parâmetro para a determinação da linha de pobreza, a regra "U\$1,00 por dia" encontram um valor para a elasticidade rendapobreza no Brasil de $(-1,09)$. No entanto, esse é único dos trabalhos encontrados que utilizam outras informações além da taxa de crescimento da renda e o índice de desigualdade como variáveis dependentes.

Além dessas, são incluídas nas estimações variáveis para captar os efeitos dos estados, assim como informações referentes aos setores da economia - agricultura, indústria e serviços. Esse resul-tado, considerando um conjunto de variáveis de controle maior é o que mais se aproxima do valor encontrado nesse trabalho.

Voltando à comparação com os trabalhos que tratam da estimação da elasticidade renda-pobreza para os estados brasileiros, alguns resultados evidenciam a relevância da inclusão das demais variáveis de controle na estimação. Inicialmente, e como observado por Barreto, Marinho e Soares (2003) e Hoffmann (2005), os estados do nordeste apresentaram elasticidades, em termos absolutos, menores do que a unidade. Todavia, os valores aqui encontrados são considera velmente maiores, à exceção do estado do Piauí, indicando que, quando considerada as especificidades locacionais, as variações na taxa de pobreza em função de variações na renda são maiores. Ainda, considerando os resultados de Hoffmann (2005), à exceção dos estados de Amapá, Piauí, Rio Grande do Norte e Sergipe, para todos os demais estados brasileiros os valores aqui encontrados foram consideravelmente maiores. Já em comparação aos resultados encontrados em Barreto, Marinho e Soares (2003), além dos pontos já ressaltados acima, chama atenção o fato dos valores aqui encontrados para os estados da região sul serem um pouco menores indicando que a inclusão das demais variáveis tornou a taxa de pobreza desses estados menos sensível à variações na renda. Todavia, esse resultado reflete as características locacionais da região, que é vista na literatura como a que apresenta os melhores indicadores de padrão de vida do país. Ou seja, e tendo em conta que as análises são feitas em cima de valores médios, as variações necessárias na renda para provocar alterações na taxa de pobreza para locais 
que apresentam médias elevadas, como a região sul, devem, necessariamente, ser maiores.

Por fim, confrontando os resultados aqui encontrados com os observados em Tochetto et al. (2004), que é o único dos trabalhos discutidos que considera outras variáveis além da renda e do índice de Gini para a estimação das elasticidades renda-pobreza, pode-se notar que, ao contrário do observado por aqueles autores, e de acordo com o esperado e o encontrado pelos demais autores citados no texto, os fatores considerados no período em análise contribuíram para diminuir a taxa de pobreza dos estados brasileiros. Embora seja necessário considerar as diferenças metodológicas, a modificação na direção com relação às variações observadas, mostra a relevância da inclusão das demais variáveis para a estimação das elasticidades renda-pobreza estaduais. Outro ponto que deve ser destacado é a diferença na magnitude dos valores encontrados, em especial para os estados da Bahia, Pernambuco e para o Distrito Federal. Nesse sentido dois pontos devem ser destacados: i) as estimações de Tochetto et al. (2004) consideram apenas o PIB não agrícola, o que limita o alcance de sua análise, ii) valores extremamente altos para a elasticidade renda-pobreza, chegando a quase 6 , indicando que uma variação de $1 \%$ na renda implica em uma variação de $6 \%$ na taxa de pobreza, foge do padrão encontrado na literatura aqui discutida.

Tabela 2 - Logaritmo da taxa de pobreza como função do logaritmo do total da renda familiar real ponderada pelo tamanho da população

\begin{tabular}{ccccccc}
\hline \multirow{2}{*}{ ltxpob } & \multicolumn{2}{c}{ MQO } & \multicolumn{2}{c}{ FE } & \multicolumn{2}{c}{ RE } \\
\cline { 2 - 7 } & Coef. & P>t & Coef. & P>t & Coef. & P>z \\
\hline lrendfamrtpop & $-0,93$ & 0,00 & $-1,07$ & 0,00 & $-0,99$ & 0,00 \\
urb & 0,39 & 0,00 & 0,35 & 0,00 & 0,36 & 0,00 \\
informal & 0,03 & 0,23 & 0,01 & 0,08 & 0,05 & 0,04 \\
integral & $-0,41$ & 0,00 & $-0,19$ & 0,02 & $-0,33$ & 0,00 \\
gini_k & 1,66 & 0,00 & 1,58 & 0,00 & 1,69 & 0,00 \\
homem & $-0,32$ & 0,47 & $-0,31$ & 0,43 & $-0,59$ & 0,14 \\
anosest & $-0,10$ & 0,32 & $-0,07$ & 0,00 & $-0,10$ & 0,27 \\
chefem & 1,13 & 0,00 & 0,20 & 0,02 & 0,76 & 0,00 \\
razdep & $-0,29$ & 0,02 & $-0,27$ & 0,00 & $-0,29$ & 0,00 \\
deseduc & 0,09 & 0,02 & 0,12 & 0,00 & 0,05 & 0,20 \\
agri & 1,91 & 0,13 & 3,65 & 0,24 & 2,67 & 0,43 \\
sup & 1,70 & 0,26 & 3,29 & 0,33 & 32,43 & 0,31 \\
medio & 1,94 & 0,14 & 3,48 & 0,16 & 2,59 & 0,18 \\
manual & 1,97 & 0,19 & 3,47 & 0,22 & 2,63 & 0,28 \\
ano & 0,00 & 0,78 & $-0,01$ & 0,00 & $-0,01$ & 0,78 \\
d1986 & $-0,05$ & 0,02 & $-0,04$ & 0,01 & $-0,04$ & 0,01 \\
d1994 & $-0,06$ & 0,04 & $-0,06$ & 0,01 & $-0,06$ & 0,02 \\
\hline & & & & & & $($ continua...)
\end{tabular}




\begin{tabular}{|c|c|c|c|c|c|c|}
\hline \multirow{2}{*}{ ltxpob } & \multicolumn{2}{|c|}{ MQO } & \multicolumn{2}{|c|}{$\mathbf{F E}$} & \multicolumn{2}{|c|}{$\mathbf{R E}$} \\
\hline & Coef. & $P>t$ & Coef. & $P>t$ & Coef. & $P>z$ \\
\hline $\mathrm{d} 2002$ & $-0,10$ & 0,01 & $-0,08$ & 0,02 & $-0,09$ & 0,01 \\
\hline intercepto & 6,15 & 0,03 & 10,76 & 0,04 & 5,14 & 0,03 \\
\hline Número de Obs. & \multicolumn{2}{|c|}{676} & \multicolumn{2}{|c|}{676} & \multicolumn{2}{|c|}{676} \\
\hline $\mathrm{R}^{2}$ & \multicolumn{2}{|c|}{0,86} & \multicolumn{2}{|c|}{0,80} & \multicolumn{2}{|c|}{0,85} \\
\hline LM & \multicolumn{2}{|c|}{234,94} & \multicolumn{2}{|c|}{ Prob $>X^{2}$} & & 0 \\
\hline Hausmann & \multicolumn{2}{|c|}{121,85} & \multicolumn{2}{|c|}{ Prob $>X^{2}$} & & 0 \\
\hline Teste $\left.F_{(18,632}\right)$ & \multicolumn{2}{|c|}{124,70} & \multicolumn{2}{|l|}{ Prob $>F$} & & 0 \\
\hline
\end{tabular}

Fonte: Elaboração própria a partir da PNAD 1981-2006.

Dado que consideramos a situação de pobreza como insuficiência de renda, esse resultado para a elasticidade renda-pobreza, além de significativo e esperado, revela aspectos importantes não só do ponto de vista individual, mas, e principalmente, do ponto de vista social. Diante da definição de pobreza aqui discutida e dentro de uma perspectiva individual, quanto maior o nível de renda do indivíduo menor será a possibilidade dele se encontrar abaixo da linha de pobreza estabelecida, independentemente das fontes de renda consideradas. Isto é, o que importa para o indivíduo, neste caso, é o volume de recursos que ele dispõe para satisfazer suas necessidades. Contudo, sendo a variável de renda uma agregação ao nível estadual, essa regra para a situação individual, embora ainda válida, deve ser ponde-rada por um conjunto de fatores relacionados ao ambiente econômico, político e social. Assim como as características individuais, as especificidades do meio no qual o indivíduo está inserido condicionam suas relações sociais determinando suas possibilidades de auferir renda. Ainda, a alta elasticidade negativa da taxa de pobreza em função da renda estadual, além de corroborar os efeitos da renda já destacados anteriormente, reforça a perspectiva da importância da capacidade de geração de renda da economia. Sem desconsiderar os efeitos da desigualdade de renda, que para uma análise sobre a economia brasileira, como destacado no trabalho, são fundamentais; estar inserido em um ambiente capaz de gerar altas taxas de crescimento econômico é decisivo para a determinação da situação de insuficiência de renda da população. Interessante observar, com relação ao conjunto de variáveis de controle nos dois modelos, os resultados apresentados pelas variáveis que compõem o conjunto de características socioeconômicas (SE), todas foram significativas - a um nível de significância de 10\% - e apresentaram o sinal esperado. Importante o resultado para a variável proporção de pessoas que vivem no meio urbano (urb) corroborando as proposições a respeito das consequências dos ciclos econômicos sobre os indivíduos que vivem em ambientes urbanos assim como o efeito tanto do setor informal quanto do trabalho 
em tempo integral na taxa de pobreza estadual. Ainda, e a mais expressiva, nota-se a relevância da desigualdade de renda na determinação da taxa de pobreza.

Para o conjunto de características demográficas (CD), algumas não foram significativas, em especial as relacionadas aos grupos de ocupação. Interessante notar, também, que no modelo 1 a variável para a razão de dependência (razdep) não foi significativa. Já no modelo 2, além de significativa, essa variável apresentou sinal negativo, refletindo que o efeito da renda, principalmente da aposentadoria, sobre a taxa de pobreza foi superior ao efeito da dependência caracterizado pelo aumento do número de idosos. Por fim, as variáveis de média de anos de estudo (anosest) e proporção de famílias chefiadas por mulheres (chefem) e a variável que capta a desigualdade educacional (deseduc) se mostraram significativas e com os sinais esperados em ambos os modelos, evidenciando, a importância da educação assim como a perspectiva de que essas famílias chefiadas por mulheres tendem a apresentar uma maior vulnerabilidade com relação à situação de pobreza. Ainda, é importante considerar os resultados apresentados pelas dummies de ano: todas se mostraram significativas e apresentaram sinal negativo, como esperado, indicando que os efeitos por elas captados contribuíram de forma positiva para a redução na taxa de pobreza.

Em suma, esses resultados indicam que, não só o crescimento econômico, mas também a estabilidade no seu comportamento ao longo do tempo, no sentido de minimizar os efeitos negativos das flutuações sobre os mais pobres, é uma estratégia condizente com a perspectiva de que reduzir a taxa de pobreza deve ser uma das prioridades dos governos.

\section{Considerações Finais}

O presente trabalho analisou as relações e os efeitos do desempenho macroeconômico sobre a taxa de pobreza. Para tanto, utilizaram-se informações sobre os estados brasileiros no período compreendido entre 1981 e 2006. Observou-se que apesar de constituírem um importante instrumento de combate à pobreza, estratégias de crescimento econômico, se tomadas isoladamente, são insuficientes. Vários aspectos estruturais condicionam as relações entre o desempenho econômico e o bem estar da população. Assim, mais que crescimento econômico contínuo, sustentável e equilibrado, é necessário romper as estruturas que, principalmente nos países subdesenvolvidos, levam ao conhecido processo de crescimento com concentração de renda. Ainda, considerando os importantes efeitos negativos que as recessões exercem sobre os mais pobres tanto no curto quanto e, principalmente, no longo prazo, uma estratégia de crescimento voltada para o combate à pobreza deve ser sustentada por políticas que minimizem as flutuações na atividade econômica, ou seja, políticas macroeconômicas com perfil anticíclico 
e dotada de instrumentos capazes de reduzir as vulnerabilidades da economia frente às crises, tanto internas quanto externas, que por ventura venham a atingi-la durante sua trajetória de crescimento.

Nesse sentido, as políticas públicas são os principais instrumentos para superar as fragilidades e as limitações do crescimento econômico e minorar a dinâmica da pobreza e da desigualdade de renda. Nesse contexto, as políticas sociais representam um importante instrumento. As políticas de transferência direta de renda vêm desempenhando relevante papel no combate à pobreza ao contribuir sobremaneira para a redução da desigualdade de renda. Esse aspecto é fundamental devido ao baixo crescimento econômico apresentado pelo país nos últimos anos. A redução da pobreza via queda na desigualdade de renda, além de uma alternativa, representa um importante instrumento na construção de uma sociedade mais justa, solidária e capaz de superar os problemas estruturais que reforçam as desigualdades e a condição de pobreza de grande parte da população.

Enfrentar a problemática da pobreza não é tarefa simples e requer tempo para que resultados consistentes sejam alcançados. No entanto, inserir o combate à pobreza no âmbito da formulação e da implementação das políticas macroeconômicas é o ponto de partida para a construção de uma agenda política voltada para a construção de uma nação menos desigual e que possibilite à sua população condições de se inserirem ativamente do meio social em que vivem exercendo de forma plena seus direitos e deveres. Aliado a esses aspectos, enfrentar os problemas estruturais que tendem a reforçar a condição da pobreza é parte importante nessa estratégia. Investir no fortalecimento e geração de emprego e renda no setor formal, considerar a importância das transformações demográficas e desenvolver políticas no sentido de minimizar os efeitos negativos dos fatores estruturais que geram desigualdades no mercado de trabalho são pontos fundamentais para que o bom desempenho macroeconômico resulte em elevação do padrão de vida da população como um todo, sendo assim, um efetivo instrumento de combate à pobreza.

Por fim, os resultados aqui encontrados devem ser tratados como indicadores de que existe um amplo campo de pesquisa a ser explorado. A identificação das relações entre o desempenho macroeconômico e a condição de pobreza não é tarefa simples, e essas relações podem ser observadas por diversas perspectivas. Como desafios para futuros trabalhos é possível utilizar informações ao nível individual para tentar identificar os determinantes individuais da condição de pobreza, sem perder em conta a relação desse indivíduo com o meio no qual ele está inserido. Ainda, considerar a probabilidade de ser pobre como variável a ser explicada, condicionada aos fatores determinados pelas variáveis independentes; e, finalmente, utilizar metodologias alternativas para a identificação das relações entre as variáveis, como, por exemplo, utilizar equações simultâneas. 


\section{Referências}

AGENOR, P. R. Business Cycles, Economic Crises, and the Poor: Testing for Asymmetric Effects. Washington, US: World Bank, 2001.

AGHION, P.; BOLTON, P. A Theory of Trickle-Down Growth and Development. Review of Economic Studies, Oxford, GB, v. 64, n. 2, p. 51-172, Apr. 1997.

AMADEO, E.; NERI, M. Macroeconomic Policy and Poverty in Brazil. Rio de Janeiro: FGV, 2000. (Ensaios Econômicos, n. 373).

ARESTIS, P. Financial Liberalization and Poverty: channels of influence. Economics Working Paper Archive, Cambridge, US, n. 411, p. 1-28, Jul. 2004.

BARRETO, F. A.; MARINHO, E.; SOARES, F. Impacto do Crescimento Econômico e da Concentração de Renda sobre a Redução da Pobreza nos Estados Brasileiros. In: ENCONTRO NACIONAL DE ECONOMIA, 31., 2003, Porto Seguro. Anais... Porto Seguro: ANPEC, 2003.

BARROS, R. P. et al. A Importância da Queda Recente da Desigualdade na Redução da Pobreza. Rio de Janeiro: IPEA, 2007b. (Texto para Discussão, n. 1256).

Demographic Changes and Poverty in Brazil. Rio de Janeiro: IPEA, 2000b. (Texto para Discussão, n. 755).

Determinantes Imediatos da Queda da Desigualdade de Renda Brasileira. Rio de Janeiro: IPEA, 2007a. (Texto para Discussão, n. 1253).

Poverty, Inequality and Macroeconomic Instability. Rio de Janeiro: IPEA, 2000a. (Texto para Discussão, n. 750).

BARROS, R. P.; MENDONÇA, R. O Impacto do Crescimento Econômico e de Reduções no Grau de Desigualdade sobre a Pobreza. Rio de Janeiro: IPEA, 1997. (Texto para Discussão, n. 528).

BARROS, R. P.; NERI, M.; MENDONÇA, R. Poverty and Inflation in Brazil: An Investigation of Their Aggregated Relationship. Rio de Janeiro: IPEA, 1995.

BAUMANN, R. Brasil: uma Década em Transição. Rio de Janeiro: Campus, 2000.

BLANK, R. Disaggregating the Effect of the Business Cycle on the Distribution of Income. Economica, London, v. 56, n. 222, p. 41-63, May 1989.

BLANK, R.; CARD, D. Poverty, income distribution and growth: are they still connected? Brookings Papers on Economic Activity, Washington, US, v. 1993, n. 2, p. 285-339, 1993. Disponível em: <http://emlab.berkeley.edu/users/card/papers/income-growth.pdf $>$. Acesso em: 05 nov. 2007

BOURGUIGNON, F. The Growth Elasticity of Poverty Reduction: Explaining Heterogeneity Across Countries and Time Periods. In: EICHER, T. S.; TURNOVSKY, S. J. (Ed.). Inequality and Growth: Theory and Policy Implications. Cambridge, US: MIT Press, 2002. p. 3-26.

The Poverty-Growth-Inequality Triangle. 2004. Disponível em: <http://siteresources. worldbank.org/DEC/Resources/847971104785060319/5988861104852366603/33634_PovertyInequalityGrowthTriangleFeb24_ICRIER.pdf>. Acesso em: 05 nov. 2007.

BRESSER-PEREIRA, L. C. B.; NAKANO, Y. Uma Estratégia de Desenvolvimento com Estabilidade. Revista de Economia Política, São Paulo, v. 22, n. 3, p. 146-180, jul./set. 2002. 
CARDOSO JÚNIOR, J. C.; JACCOUD, L. Políticas Sociais no Brasil: Organização, Abrangência e Tensões da Ação Estatal. In: JACCOUD, L. (Org.). Questão Social e Políticas Sociais no Brasil Contemporâneo. Brasília: IPEA, 2005. Cap. 5, p. 181-260.

CARDOSO JÚNIOR, J. C. Estrutura Setorial-Ocupacional do Emprego no Brasil e Evolução do Perfil Distributivo nos Anos 90. Rio de Janeiro: IPEA, 1999. (Texto para Discussão, n. 655).

CASTRO, J. A.; CARDOSO JÚNIOR, J. C. Políticas Sociais no Brasil: Gasto Social do Governo Federal de 1988 a 2002. In: JACCOUD, L. (Org.). Questão Social e Políticas Sociais no Brasil Contemporâneo. Brasília: IPEA, 2005. Cap. 6, p. 261-318.

COURSEIUL, C.M.; FOGUEL, M.N. Uma sugestão de Deflatores para Rendas Obtidas a partir de algumas Pesquisas Domicialiares do IBGE. Brasília, DF: IPEA, jul. 2002. (Texto para discussão, n. 897).

CUTLER, D.; KATZ, L. Macroeconomic Performance and the Disadvantaged. Brookings Papers on Economic Activity, Washington, US, v. 22, n. 2, p. 285-339, 1993.

DINIZ, C. C. Repensando a Questão Regional Brasileira: Tendências, Desafios e Caminhos. In: CASTRO, A. C. (Org.). Desenvolvimento em Debate: Painéis do Desenvolvimento Brasileiro II. Rio de Janeiro: Manaud: BNDES, 2002. v. 3, p. 239-274.

DINIZ, C. C.; GONÇALVES, E. Economia do Conhecimento e Desenvolvimento Regional no Brasil. In: DINIZ, C. C.; LEMOS, M. B. (Org.). Economia e Território. Belo Horizonte: Ed. da UFMG, 2005. Vol. 1, p. 131-170.

DINIZ, C. C.; LEMOS, M. B. Dinâmica regional e suas perspectivas no Brasil. In: AFFONSO, R. B. A.; SILVA, P. L. B. (Org.). A Federação em Perspectivas: Ensaios Selecionados. São Paulo: FUNDAP, 1995. p. 417-430.

DOLLAR, D.; KRAAY, A. Growth is Good for the Poor. Journal of Economic Growth, Norwell, US, v. 7, n. 3, p. 195 - 225, Sept. 2002.

FERREIRA, F. H. G. et al. Protecting the Poor from Macroeconomic Shocks: An Agenda for Action in a Crisis and Beyond. Policy Research Working Paper, Washington, US, n. 2160, 2000.

FERREIRA, F.H.G.; LITCHFIELD, J. A. Growing Apart: Micro and Macroeconomic Factors behind the Brazilian Income Distribution, 1981-1990. Rio de Janeiro: IPEA, 1996. (Seminários, n. 22).

FERREIRA, F. H. G.; LEITE, P. G.; RAVALLION, M. Poverty Reduction without Economic Growth? Explaining Brazil's Poverty Dynamics, 1985-2004. Policy Research Working Paper, Washington, US, n. 4431, 2007.

FOSU, A. K. Growth, Inequality and Poverty Reduction in Development Countries Recent Global Evidence. Background Paper for the Global Development Outlook 2010. Paris: OCDE, 2010.

FREEMAN, R. The Rising Tide Lifts...? NBER Working Paper, Chicago, US, n. 8155, 2001.

HINES, J. R.; HOYNES, H.; KRUEGER, A. B. Another Look at Whether a Rising Tide Lifts All Hoats. NBER Working Paper, Chicago, US, n. 8412, 2001.

HOFFMANN, R. Elasticidade da Pobreza em Relação à Renda Média e à Desigualdade no Brasil e nas Unidades da Federação. Economia, Brasília, v. 6, n. 2, p. 255-289, 2005.

INSTITUTO DE PESQUISA ECONÔMICA APLICADA (IPEA). Sobre a Recente Queda da Desigualdade no Brasil. Brasília, 2006. (Nota Técnica, n. 9). 
KAKWANI, N. Poverty and Economic Growth: With Application to Côte d'Ivoire. Review of Income and Wealth, New Haven, US, v. 39, n. 2, p. 121-139, Jun. 1993.

LUSTIG, N. Crises and the Poor: Socially Responsible Macroeconomics. IDB Publications, Washington, US, n. 29338, Feb. 2000.

MENEZES, T.; AZZONI, C. Convergência de Renda Real e Nominal Entre as Regiões Metropolitanas Brasileiras: Uma Análise de Dados de Painel. São Paulo: FEA/USP, 1999. (mimeo).

NERI, M. C.; THOMAS, M. R. Macro Shocks and Microeconomic Instability: An Episodic Analysis of Booms and Recessions. Rio de Janeiro: FGV, 2000. (Ensaios Econômicos, n. 391).

RAMOS, L.; VIEIRA, M. L. Desigualdade de Rendimentos no Brasil nas Décadas de 80 e 90: Evolução e Principais Determinantes. Rio de Janeiro: IPEA, 2001. (Texto para Discussão, n. 803).

RAVALLION, M.; DATT, G. Growth and Redistribution Components of Changes in Poverty Measures: A Decomposition with Applications to Brazil and India in the 1980s. Journal of Development Economics, Amsterdam, NL, v. 38, p. 275-295, 1992.

Why has Economic Growth Been More Pro-Poor in Some States of India than Others? Journal of Development Economics, v. 68, n. 2, p. 381-400, 2002.

RAVALLION., M.; CHEN, S. What can new survey data tell us about recent changes in distribution and poverty? Policy Research Working Paper, Washington, US, n. 1694, 1996.

RAVALLION, M. A Comparative Perspective on Poverty Reduction in Brazil, China and India. Policy Research Working Paper, Washington, US, n. 5080, 2009.

ROCHA, S. Do Consumo Observado à Linha de Pobreza. Pesquisa e Planejamento Econômico, Rio de Janeiro, v. 27, n. 2, p. 313-352, ago. 1997.

Pobreza e Desigualdade no Brasil: O Esgotamento dos Efeitos Distributivos do Plano Real. Rio de Janeiro: IPEA, 2000. (Texto para Discussão, n.721).

RODRIGUEZ, O. Teoria do Subdesenvolvimento da CEPAL. Rio de Janeiro: Forense, 1981.

SOARES, F. V. et al. Programas de Transferência de Renda no Brasil: Impactos sobre a Desigualdade. Rio de Janeiro: IPEA, 2006. (Texto para Discussão, n. 1228).

SON, H. H. A Note on Pro-Poor Growth. Economics Letters, Amsterdam, NL, v. 82, p. 307304, 2004

STALLINGS, B; PERES, W. Crescimento, Emprego e Equidade: O Impacto das Reformas Econômicas na América Latina e Caribe. Rio de Janeiro: Campus: CEPAL, 2002.

THIRLWALl, A. P. A Natureza do Crescimento Econômico: Um Referencial Alternativo para Compreender o Desempenho das Nações. Brasília: IPEA, 2005.

TOCHETTO, D. G. et al. Crescimento Pró-Pobre no Brasil: Uma Análise Exploratória. In: ENCONTRO NACIONAL DE ECONOMIA, 32., 2004, João Pessoa. Anais... João Pessoa: ANPEC, 2004

WOOLDRIDGE, J. M. Econometric Analysis of Cross Section and Panel Data. Cambridge, US: MIT Press, 2002. 


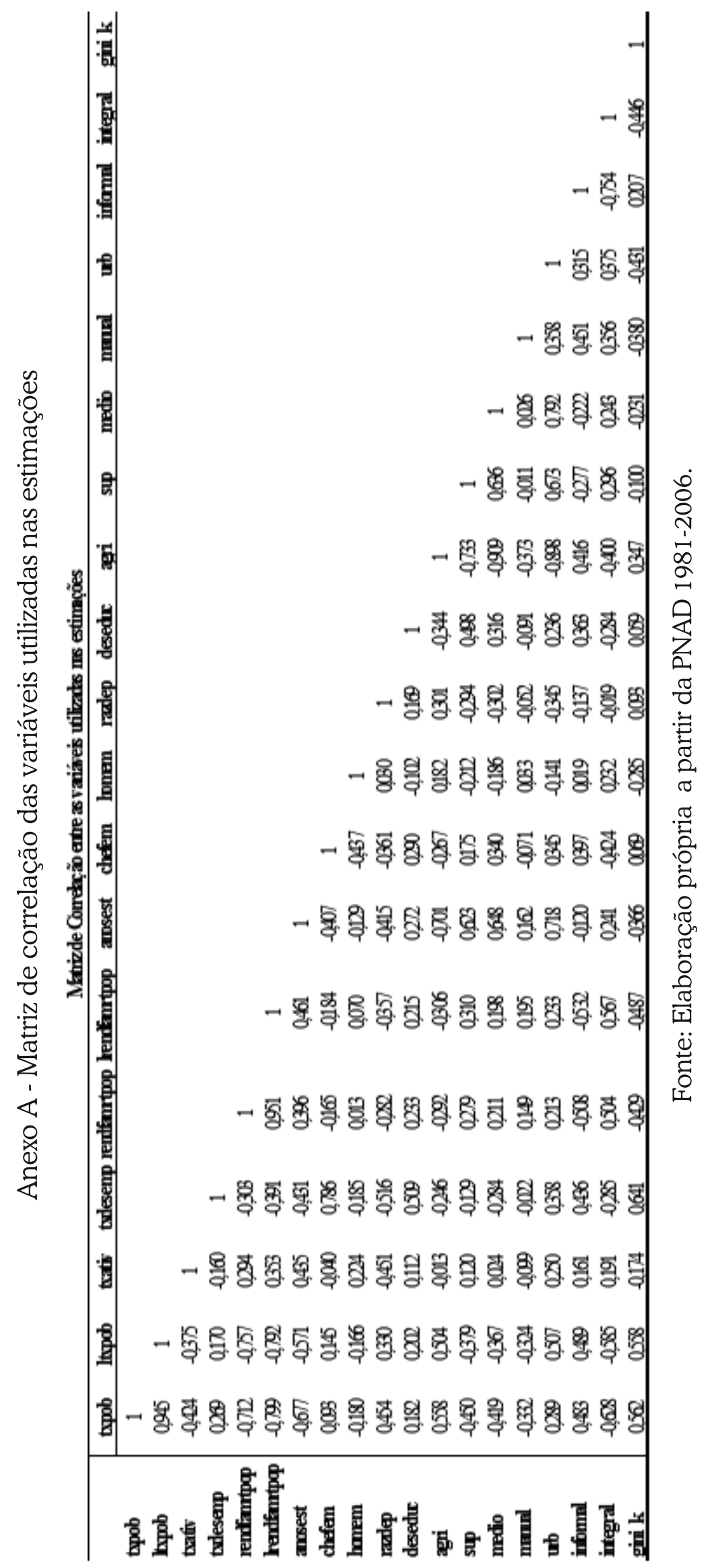


Anexo B - Estatísticas descritivas das variáveis utilizadas nas estimações Estatísticas Descritivas das variáveis utilizadas

\begin{tabular}{|c|c|c|c|c|c|}
\hline Variável & Num. obs & Média & $\begin{array}{l}\text { Desvio } \\
\text { padrão }\end{array}$ & $\begin{array}{c}\text { Valor } \\
\text { mínimo }\end{array}$ & $\begin{array}{c}\text { Valor } \\
\text { máximo }\end{array}$ \\
\hline txpob & 676 & 42,23 & 18,16 & 1,98 & 63,29 \\
\hline ltxpob & 676 & 1,58 & 0,23 & 0,30 & 1,80 \\
\hline txativ & 676 & 56,50 & 3,79 & 43,09 & 64,77 \\
\hline txdesemp & 676 & 10,20 & 6,60 & 2,53 & 32,65 \\
\hline rendfamrtpop & 676 & $1.407 .454,00$ & $688.294,20$ & $527.124,50$ & $6.922 .976,00$ \\
\hline Irendfamrtpop & 676 & 6,11 & 0,18 & 5,72 & 6,84 \\
\hline anosest & 676 & 4,27 & 1,11 & 1,61 & 7,23 \\
\hline chefem & 676 & 0,21 & 0,05 & 0,08 & 0,41 \\
\hline homem & 676 & 0,49 & 0,01 & 0,45 & 0,53 \\
\hline razdep & 676 & 0,39 & 0,07 & 0,26 & 0,67 \\
\hline deseduc & 676 & 0,30 & 0,21 & 0,10 & 1,12 \\
\hline agri & 676 & 0,25 & 0,15 & 0,12 & 0,64 \\
\hline sup & 676 & 0,12 & 0,04 & 0,04 & 0,35 \\
\hline medio & 676 & 0,42 & 0,10 & 0,18 & 0,75 \\
\hline manual & 676 & 0,21 & 0,05 & 0,06 & 0,54 \\
\hline urb & 676 & 0,77 & 0,17 & 0,34 & $1,00^{*}$ \\
\hline informal & 676 & 0,50 & 0,17 & 0,16 & 0,67 \\
\hline integral & 676 & 0,76 & 0,09 & 0,42 & 0,80 \\
\hline gini_k & 676 & 0,57 & 0,04 & 0,40 & 0,68 \\
\hline
\end{tabular}

Fonte: Elaboração própria a partir da PNAD 1981-2006.

Nota: * Esse valor é função das limitações de abrangência da PNAD para algumas localidades. 
Anexo C - Comparação das estimativas para a elasticidade renda-pobreza estadual

\begin{tabular}{|c|c|c|c|c|}
\hline & Resultados & $\begin{array}{c}\text { Tochetto et } \\
\text { al.* }\end{array}$ & Marinho** & Hoffmann*** \\
\hline Rondônia & $-1,414$ & - & $-1,38$ & $-0,92$ \\
\hline Acre & $-0,853$ & - & $-1,20$ & $-0,74$ \\
\hline Amazonas & $-1,282$ & - & $-1,03$ & $-0,74$ \\
\hline Roraima & $-2,568$ & - & $-1,56$ & $-0,90$ \\
\hline Pará & $-1,449$ & $-0,105$ & $-1,05$ & $-0,78$ \\
\hline Amapá & $-1,048$ & - & $-1,15$ & $-1,28$ \\
\hline Maranhão & $-0,692$ & - & $-0,60$ & $-0,52$ \\
\hline Piauí & $-0,445$ & - & $-0,52$ & $-0,52$ \\
\hline Ceará & $-0,755$ & $-2,718$ & $-0,63$ & $-0,53$ \\
\hline Rio Grande do Norte & $-0,622$ & - & $-0,86$ & $-0,64$ \\
\hline Paraíba & $-0,719$ & - & $-0,81$ & $-0,56$ \\
\hline Pernambuco & $-0,925$ & 5,938 & $-0,78$ & $-0,56$ \\
\hline Alagoas & $-0,946$ & - & $-0,71$ & $-0,49$ \\
\hline Sergipe & $-0,474$ & - & $-0,79$ & $-0,64$ \\
\hline Bahia & $-0,897$ & 5,939 & $-0,75$ & $-0,56$ \\
\hline Minas Gerais & $-1,320$ & 1,339 & $-1,22$ & $-0,92$ \\
\hline Espírito Santo & $-1,501$ & - & $-1,24$ & $-0,82$ \\
\hline Rio de Janeiro & $-1,588$ & 1,309 & $-1,64$ & $-1,13$ \\
\hline São Paulo & $-1,910$ & 1,337 & $-1,74$ & $-1,27$ \\
\hline Paraná & $-1,131$ & 0,713 & $-1,33$ & $-1,01$ \\
\hline Santa Catarina & $-1,521$ & - & $-1,59$ & $-1,47$ \\
\hline Rio Grande do Sul & $-1,373$ & 0,417 & $-1,51$ & $-1,14$ \\
\hline Mato Grosso do Sul & $-1,743$ & - & $-1,27$ & $-0,95$ \\
\hline Mato Grosso & $-1,278$ & - & $-1,29$ & $-0,92$ \\
\hline Goiás & $-1,430$ & - & $-1,01$ & $-0,91$ \\
\hline Distrito Federal & $-1,780$ & $-4,160$ & - & $-1,04$ \\
\hline Brasil & $-1,070$ & - & - & $-0,84$ \\
\hline
\end{tabular}

Fonte: Elaboração própria.

Nota: * Informações considerando o período 1981 - 2002; * Informações para o último ano apresentado no trabalho, a saber: $1999 ; * *$ *Informações para o último ano apresentado no trabalho, a saber: 2002.

Recebido em: 13/04/2011. Aceito em: 08/05/2012. 